\title{
Soot Formation in Non-Premixed Counterflow Flames of Butane and Butanol Isomers
}

\author{
Pradeep Singh ${ }^{1}$, Xin Hui ${ }^{1,2}$, and Chih-Jen Sung ${ }^{1}$ \\ ${ }^{1}$ Department of Mechanical Engineering \\ University of Connecticut \\ Storrs, CT 06269, USA \\ ${ }^{2}$ National Key Laboratory of Science and Technology on Aero-Engine Aero-Thermodynamics \\ School of Energy and Power Engineering \\ Beihang University \\ Beijing, 100191, P.R. China
}

Keywords: Butanol Isomers, Butane Isomers, Soot Formation, Laser-Induced Incandescence, Light Extinction, Non-Premixed Counterflow Flames

\author{
Corresponding Author: \\ Xin Hui \\ National Key Laboratory of Science and Technology on Aero-Engine Aero-Thermodynamics \\ School of Energy and Power Engineering \\ Beihang University \\ Beijing, 100191, P.R. China \\ Email: huixin@buaa.edu.cn
}

Submitted for publication in Combustion and Flame

November 13, 2015

Manuscript Reference Number: CNF-D-15-00492R2

\author{
(C) 2015. This manuscript version is made available under the Elsevier user license \\ http:/www.elsevier.com/open-access/userlicense/1.0/
}




\author{
Soot Formation in Non-Premixed Counterflow Flames of Butane and Butanol Isomers \\ Pradeep Singh ${ }^{1}$, Xin Hui ${ }^{1,2}$, and Chih-Jen Sung ${ }^{1}$ \\ ${ }^{1}$ Department of Mechanical Engineering \\ University of Connecticut, Storrs, CT 06269, USA \\ ${ }^{2}$ National Key Laboratory of Science and Technology on Aero-Engine Aero-Thermodynamics \\ School of Energy and Power Engineering \\ Beihang University, Beijing, 100191, P.R. China
}

\begin{abstract}
Soot formation processes for butane and butanol isomers have been experimentally investigated and compared in a counterflow non-premixed flame configuration at atmospheric pressure. Nonintrusive laser-based diagnostic techniques, including Laser Induced Incandescence and Light Extinction, have been adopted for soot volume fraction measurements. Experimental results of these $\mathrm{C}_{4}$ fuels have been compared to illustrate the effects of hydroxyl (-OH) group and the isomeric structures on soot formation process. Under the investigated conditions, butane isomers were observed to form more soot than butanol isomers, thereby showing the effect of the hydroxyl group. The effects of isomeric structural differences on sooting propensity were also observed within the butane and butanol isomers. In addition, while soot volume fraction was seen to increase with increasing fuel mole fraction, the ranking of sooting propensity for these $\mathrm{C}_{4}$ fuels remained unchanged. Effects of varying strain rate and oxygen mole fraction on soot formation were studied herein as well. For each isomeric class, two chemical kinetic models available in the literature were used to simulate and compare the spatially-resolved profiles of the soot precursors. The amount of soot precursors predicted by the models were different and the initial fuel breaking pathways were also found to differ significantly. Furthermore, no direct correlation between the computed mole fractions of soot precursors and the measured amount of soot formed in the present experimental conditions was observed.
\end{abstract}




\section{Introduction}

Currently, $80 \%$ of world energy demand is met by using fossil fuels [1]. With the projected world energy demand expected to triple by the end of this century [1], alternative and renewable means of energy resources have huge potential in meeting the ever increasing world energy demand. Biofuels, amongst many other alternative sources of energy, offer multiple benefits in terms of providing energy security, economic advantages, and environmental protection [1].

Extensive research has been conducted on biofuels that are produced from the biomass [2]. The so-called second generation biofuels do not pose a threat to food security as these biofuels can be produced from inedible crops [2]. Butanols are second generation biofuels, which are considered as a substitute to currently used first generation ethanol as blend in gasoline. Butanol isomers are high in energy density (36 MJ/kg) compared to ethanol (27 MJ/kg) [3]. Additionally, butanol isomers except for tert-butanol are less miscible in water than ethanol, and hence provide ease in fuel distribution through existing infrastructure [2]. Biochemical processes for butanol isomers production, except for tert-butanol, have been established and are less capital intensive $[2,4]$. tert-Butanol that is derived as a petroleum by-product from the propylene oxide, is often used as an octane enhancer in gasoline [5].

As biofuels are considered for practical applications, interest of the research community in fundamental research for butanol isomers has been increasing. The investigation of their fundamental properties assists in the design of advanced engines to control the combustion processes. This is evident as there have been numerous fundamental combustion studies of butanols conducted on laminar premixed and non-premixed flames [e.g., 6-25], flow reactors [e.g., 26-31], ignition delays in shock tubes [e.g., 32-41] and rapid compression machines [e.g., 42-45], fuel pyrolysis [e.g., 46-50], and jet stirred reactors [e.g., 7,13,19,51-56]. In addition, 
engine studies were conducted for butanol isomers to determine brake specific fuel consumption, exhaust gas temperature, and thermal efficiency [e.g., 57-62].

Along with the aforementioned studies, it is also imperative to conduct studies related to carbonaceous emissions. Soot is combustion generated carbonaceous particulate matter which has been considered responsible for climate change and health problems. As soot formation adversely affects the performance and lifetime of practical combustors and engines, understanding soot formation processes for different conventional and alternative fuels in flames is vitally important to rationalize their use as a potential source of energy [63]. The $\mathrm{C}_{4}$ fuels investigated in this study are $n$ - and iso-butanes, as well as $n$-, iso-, sec-, and tert-butanols. The structures of these fuels are shown in Table 1. By comparing butanol and butane isomers, it allowed us to investigate the effects of hydroxyl (-OH) group and the isomeric structures on sooting tendency.

Previously, Camacho et al. [63] studied the sooting characteristics of $n$-butane, iso-butane, $n$-butanol, and iso-butanol in a burner stabilized stagnation premixed flame configuration to investigate the impact of fuel bound hydroxyl group, as well as the effect of fuel structure. They found that under the same $\mathrm{C} / \mathrm{O}$ ratio, butanol flames nucleate sooner than butane flames. It was concluded by Camacho et al. [63] that the sooting behavior in the premixed flames at the nucleation stage can be predicted by the soot precursors, while at the mass growth stage the relationship between the predicted benzene concentration and the sooting behavior becomes less clear, considering the complexity of soot formation process. McEnally and Pfefferle [64] studied the sooting behavior of butanol isomers by doping $3500 \mathrm{ppm}$ of each of butane and butanol isomers in a coflow methane-air non-premixed flame. They found that benzene formation is directly linked to propargyl $\left(\mathrm{C}_{3} \mathrm{H}_{3}\right)$ species concentration. It is noted that both the studies of 
Camacho et al. [63] and McEnally and Pfefferle [64] have focused on the incipient soot formation process.

To our knowledge, none of the literature studies have been conducted to investigate the soot formation of these butanol isomers in a non-premixed counterflow flame configuration, and all the butanol isomers have not been compared with the butane isomers in such a sooting flame configuration. Counterflow non-premixed flame is known to provide an aerodynamically-clean and well-characterized configuration for experiments and simulations. With judicious mixture compositions for the fuel and oxidizer streams, the resulting non-premixed flame can be situated at different locations relative to the stagnation surface so that it is possible to separate the processes of soot formation and oxidation for further characterization. In this study, the sooting behavior of each flame is characterized and determined by measuring its spatially-resolved soot volume fraction profile.

Various techniques of soot measurement, such as gravimetric sampling, condensation particle counters, differential mobility particle sizer, and transmission electron microscopy using thermophoretic sampling, have been developed [65]. These techniques rely on the collection of soot particles manually, examining them by their physical parameters, such as weight, particle mobility in an electric field, etc., and the use of a microscope. As such, these sampling techniques are time consuming and some of them are intrusive. Faster, non-intrusive optical techniques have been developed to characterize soot formation in combustion. Two such laserbased techniques of soot particle measurements, namely Laser Induced Incandescence (LII) and Light Extinction (LE), have been used in the present study. In particular, the use of planar LII imaging in conjunction with line-of-sight LE calibration technique provides very fast, quantitative, and spatially-resolved soot volume fraction measurements. 
In the following, we will first specify the experimental details, including a counterflow burner facility, LII/LE setup, calibration procedure using the LE technique to determine a calibration factor to convert the LII signals into quantitative soot volume fraction measurements, and the current test matrix. Next, the computational methodology and the literature reaction mechanisms employed to simulate the counterflow flame structures at varying experimental conditions will be introduced. Subsequently, the experimental results of butane isomers and butanol isomers with variations of strain rate, fuel loading, and oxygen mole fraction will be presented and compared, followed by the discussion of computational results, including flame structure, concentrations of soot precursors, and chemical kinetic analyses based on gas-phase chemistry.

\section{Experimental specifications}

\subsection{Counterflow burner facility}

A counterflow burner facility was used to establish a non-premixed flame. The burner consisted of two aerodynamically converging opposing nozzles of $10 \mathrm{~mm}$ exit diameter with a separation distance of $L=11 \mathrm{~mm}$. More details on this burner facility can be found in [66,67], and hence a brief description of the system setup is given below. Liquid fuels were injected using a high precision liquid fuel pump, and were vaporized by providing heated annular coflow of heated nitrogen in the vaporization chamber. The gaseous fuels, namely butane isomers, were introduced using a mass flow controller, capable of controlling flow rates as low as 20 standard cubic centimeters per minute. The fuel/nitrogen mixture was introduced from the bottom nozzle, while nitrogen and oxygen were mixed in a separate line and introduced from the top nozzle. 
Supply lines from the flow panel to the bottom nozzle were maintained at an appropriate temperature by using heating tapes to prevent condensation of liquid fuels.

\subsection{Laser induced incandescence}

Laser Induced Incandescence (LII) has been widely used technique for soot measurements [e.g., 68-90]. In the LII technique, a Continuum Powerlite 8010 Nd:YAG laser was used to provide a laser output of $532 \mathrm{~nm}$ wavelength (the second harmonic) at $10 \mathrm{~Hz}$ repetition rate. This visible wavelength facilitates precise laser sheet alignment in the center of the burner, which is crucial in soot measurements as the soot volume fraction varies radially. Since the primary soot particle sizes are expected to be in the range of $2-90 \mathrm{~nm}$, the wavelength of $532 \mathrm{~nm}$ also fulfills the Rayleigh absorption criterion of $\frac{\pi D}{\lambda} \ll 1$, where $D$ is the diameter of the soot particle and $\lambda$ is the laser wavelength. The laser beam has a Gaussian profile with the least square factor of 0.95 , and the laser power used for the LII measurements was $220 \mathrm{~mW}$. The short laser pulse width of $7 \mathrm{~ns}$ results in rapid heating of soot particles, as seen from a representative temporal profile of LII signal shown in Fig. 1. It is noted that the LII signal profile in Fig. 1 is normalized with the maximum LII signal. The laser beam was guided in the sooting zone using dichroic mirrors. The propagating laser beam has a uniform beam diameter of $8 \mathrm{~mm}$, as the Gaussian beam remains uniform with a very small beam divergence angle of 0.45 mrads. A laser sheet was formed by expanding the laser beam vertically with an expansion factor of 15, through the use of a cylindrical plano-concave lens with a focal length of $f=-25.7 \mathrm{~mm}$ and a cylindrical planoconvex lens of $f=250 \mathrm{~mm}$. Due to the large vertical expansion, the energy distribution in the laser sheet along the vertical direction was uniform. An iris was also used to focus the central part of the laser sheet between the fuel and oxidizer nozzles. 
The LII signal was detected in a Peltier cooled intensified CCD camera (Princeton Instrument, PIMAX-3), which has a quantum efficiency of $15 \%$ for the detection wavelength of $450 \mathrm{~nm}$. The selection of this particular wavelength will be discussed in details later. With the current optical setup, the spatial resolution was $0.0384 \mathrm{~mm} /$ pixel. The intensified CCD camera was synchronized with the laser using an external trigger from the laser. While the delay settings on the camera will be described in due course, briefly, its selection was set such that the camera shutter would open after the laser pulse arrives in the sooting zone and the subsequent heating of the soot particles is achieved. Although the laser pulses reached the sooting zone at a repetition rate of $10 \mathrm{~Hz}$, the soot measurements were conducted at the nanosecond time scale. Such nanoscale measurements permit sufficient time for LII detections between two consecutive laser pulses.

The theoretical basis of LII process is based on transient energy balance mechanism. When soot particles are heated up due to absorption of laser energy, there is a rapid increase in internal energy of the soot particle. The sudden heating of soot particle raises the particle temperature to $4000 \mathrm{~K}$ [81]. After attaining such high temperature, the soot particles cool down due to sublimation, convection, and radiation. The nearly blackbody emission signals due to the radiative cooling process of the soot particles are detected as the LII signals [82]. Because of very high temperatures, sublimation of $\mathrm{C}_{2}$ species occurs from the soot particle surface, which generates spectroscopic emissions [83]. These $C_{2}$ emissions have a wavelength region of 420-650 $\mathrm{nm}$ in the Swan band [83], they are a major cause of interference in the LII signal.

In order to determine the exact settings of gate delay and gate width for the experiments, the temporal measurement of LII signal was first analyzed. Figure 1 shows a temporal profile of LII signal, with time "0" corresponding to the time when the laser pulse arrives the sooting zone. 
This profile shows a sharp rise in the LII signal as the soot particles are heated rapidly by a short (7 ns) laser pulse. After attaining a peak value, the LII signal first decays sharply due to the rapid sublimation cooling process of soot particles [82,83], and then decays slowly after around $40 \mathrm{ns,}$ as the cooling is subsequently dominated by the slower convective heat transfer process. It is further noted that the cooling rate of a soot particle is proportional to its surface area/volume ratio, which can be expressed as $\frac{D^{2}}{D^{3}} \sim \frac{1}{D}$. Thus, smaller soot particles cool down faster, creating a bias towards larger soot particles when a long gate width is used. Two gating approaches, namely prompt and delayed gatings, have been adopted by various researchers [81-83] for the LII signal. In the prompt gating approach, the gate width opening time is right at the peak of the LII signal. After this peak the cooling process starts. Although the advantage of this approach is that the LII signal avoids the bias created by the particles of larger sizes, however it cannot avoid interferences due to the $\mathrm{C}_{2}$ emissions. In the delayed gating approach, the gating starts after rapid cooling process is over in the LII signal, e.g., around $40 \mathrm{~ns}$ in Fig. 1. This gating approach is capable of avoiding the $\mathrm{C}_{2}$ interferences; however, it tends to include bias due to the slower cooling rate of larger soot particles as discussed earlier. Therefore, a balanced approach of choosing a setting between prompt and delayed gatings was adopted herein to optimize the LII signal [81-83].

As mentioned earlier, at the onset of the sublimation process, the $\mathrm{C}_{2}$ emissions due to fluorescence process start, but such interferences have a very short lifetime of approximately 5 ns scale. Since the LII signal peaks at 20 ns, as shown in Fig. 1, in the present study the LII data were measured at a gate delay of $25 \mathrm{~ns}$. This further $5 \mathrm{~ns}$ delay from the peak LII signal was found to be adequate in avoiding the $\mathrm{C}_{2}$ Swan band interferences from vaporized soot particles. In addition, a gate width of $80 \mathrm{~ns}$ was selected to avoid the particle size bias in the LII signal. 
This gate width was not shortened further as it was observed that the $80 \mathrm{~ns}$ gate width was sufficient in providing strong LII signals for all the flame conditions investigated in this study.

To examine the dependence of the LII signal on varying laser fluence, the laser pulse energy was varied with Q-switch delays in Nd:YAG laser. Laser fluence was calculated as per standard practice of fluence per pulse energy [83]. Since there are soot particles of different sizes and the cooling rate of a particle is dependent on the particle diameter, the LII signal from particles of different sizes may have varying response to the laser fluence. Hence, when determining experimentally-viable laser fluence, the LII signal was integrated for the entire flame, including soot particles of various diameters, so that the spatially-integrated LII signal addresses any bias due to varying particle sizes. Figure 2 shows that an increase in laser fluence results in stronger integrated LII signal, due to the increase in temperature of the soot particles. When the internal energy increases up to a certain point, soot particles attain a temperature where sublimation process starts, and further increasing the laser fluence does not increase the integrated LII signal anymore [81,84-86]. Again, the integrated LII signal in Fig. 2 is normalized with the maximum value. As shown in Fig. 2, LII signal saturates for the laser fluence beyond a threshold value of $\sim 0.50 \mathrm{~J} / \mathrm{cm}^{2}$. Selecting laser fluence below the threshold value leads to unwanted LII signal-tosignal variation as the soot particle heating process has not yet attained the steady state $[82,83]$. Hence, the laser fluence of $0.58 \mathrm{~J} / \mathrm{cm}^{2}$ was chosen for the current experiments. We further note that in Fig. 2 a decrease in the LII signal beyond $0.6 \mathrm{~J} / \mathrm{cm}^{2}$ is observed, which may be caused by the particle size reduction due to the sublimation from the surface of the soot particle at higher fluence [87]. As the laser sheet passes through the flame, some of the laser energy is absorbed by the soot particles along the pathway. This absorption may result in bringing the laser fluence below the threshold value across the flame. However, as it is evident from the symmetrical 
profile of the LII signal shown in Fig. 3 (to be discussed in due course) that the laser fluence of $0.58 \mathrm{~J} / \mathrm{cm}^{2}$ was sufficient to maintain the laser fluence above the threshold value.

A narrow band filter centered at $450 \pm 10 \mathrm{~nm}$ was used for the present LII measurements. This detection wavelength was selected to avoid/minimize the $\mathrm{C}_{2}$ Swan band emissions [83]. Polycyclic aromatic hydrocarbons (PAHs) are also known to absorb laser in the UV and visible range, and their fluorescence signals are red shifted [88]. In particular, absorption of $532 \mathrm{~nm}$ wavelength laser light by PAHs would emit fluorescence at wavelengths greater than $532 \mathrm{~nm}$. Thus, the use of this narrow band filter centering at $450 \mathrm{~nm}$ for LII detection also avoids the PAH fluorescence [88]. We further note that blue-shifted laser induced fluorescence (LIF) signal has been observed in recent studies [91,92]. Especially, Bejaoui et al. [91] showed that excitation at $532 \mathrm{~nm}$ results in fluorescence emission in the range of 370-720 nm. However, since LIF signal is typically short lived ( $10 \mathrm{~ns})$, the use of delayed gating of $25 \mathrm{~ns}$ in the present LII measurements can avoid the potential interference of blue-shifted LIF signals.

There have been many theoretical and experimental studies conducted to correlate the LII signal with the soot volume fraction. Primary soot particle sizes are small enough to fulfill the critical Rayleigh criterion of scattering, $\frac{\pi D}{\lambda} \ll 1$, with $\lambda=532 \mathrm{~nm}$. Following the study of [89], Eq. (1) defines the theoretical approach of LII measurement:

$L I I \propto \pi D^{2} N \int_{0}^{\tau} M(t) w(t) \int_{\lambda_{1}}^{\lambda_{2}} G_{r}(\lambda) \varepsilon(D, \lambda) E_{b}(T, \lambda) d \lambda d t$,

where $L I I$ is the LII signal intensity, $N$ is the soot particle number density, $M(t)$ denotes the mass concentration as a function of time, $w(t)$ is a window function representing the signal collection gate width, whose duration is $\tau, G_{r}(\lambda)$ is the relative response of the detector and the filter used, which is a function of detection wavelength, $\varepsilon(D, \lambda)$ is the emissivity of soot particle, which is a function of soot particle diameter and detection wavelength, and $E_{b}(T, \lambda)$ denotes 
spectral radiance which is a function of wavelength and absolute temperature $T$. Further, the LII signal in Eq. (1) is shown by [84] to be proportional to the soot volume fraction, $f_{v}$, as expressed in Eq. (2):

$L I I \propto f_{v}=N \frac{\pi D^{3}}{6}$.

Theoretical model developed by Melton [90] using the energy balance equation for soot particles has shown that the LII signal detected at wavelength $\lambda_{\text {det }}$ (in $\mu \mathrm{m}$ ) is proportional to $D^{3+0.154 / \lambda_{\text {det }}}$. Selection of $\lambda_{\text {det }}=0.450 \mu \mathrm{m}$ brings the LII signal to be proportional to $D^{3}$, i.e. the soot particle volume. A good agreement has been shown between the soot volume fraction measured using the laser light extinction technique and the LII results using $450 \mathrm{~nm}(0.450 \mu \mathrm{m})$ detection wavelength $[82,84]$. Experimentally, many studies [e.g., 84,88$]$ have also shown that the LII signal is proportional to the soot volume fraction.

\subsection{Laser light extinction}

The light extinction (LE) technique is a traditional in-situ non-intrusive diagnostics to measure the soot volume fraction quantitatively $[90,93]$. This technique is a line-of-sight measurement. Here, a helium-neon (He-Ne) laser was used, which provided continuous laser beam at $632.8 \mathrm{~nm}$ wavelength. As such, this light extinction technique also relies on the Rayleigh absorption criterion discussed earlier.

The He-Ne laser beam was focused in the flame using a biconvex lens of focal length $f=170$ $\mathrm{mm}$. A mechanical chopper was used to modulate the laser beam at $1000 \mathrm{~Hz}$, and a photodetector was used to detect the signal. In order to prevent the noise in the signal due to the flame luminosity and the room light, a laser line interference filter centered at $632 \mathrm{~nm}$ was installed in front of the detector. The reference frequency of laser beam modulation from the mechanical 
chopper was sent to a lock-in-amplifier. Only the laser signal at $1000 \mathrm{~Hz}$ was processed by the lock-in-amplifier, rejecting any noise present in the signal. Then, the signal from the lock-inamplifier was read in a computer using the LabView software to determine the absorption ratio. A vertical translation stage with minimum step size of $0.01 \mathrm{~mm}$ was used to adjust the height of measurement in the flame. A horizontal translation stage with minimum step size of $0.01 \mathrm{~mm}$ was also used to scan the flame radially.

The absorption of laser light across the flame in the finite path length, $\ell$, as per the Bouguer's Law, is given by Eq. (3):

$\frac{\mathrm{I}}{\mathrm{I}_{\mathrm{o}}}=\mathrm{e}^{-\mathrm{K}_{\mathrm{ext}} \ell}$,

where $I_{0}$ is the intensity of the incident laser beam, $I$ is the intensity of laser beam after absorption by soot particles, and $\mathrm{K}_{\mathrm{ext}}$ is the extinction coefficient. As the scattering is small compared to the absorption in the Rayleigh limit, $\mathrm{K}_{\mathrm{ext}}$ is approximated by the following expression:

$\mathrm{K}_{\mathrm{ext}}(r)=\mathrm{K}_{\mathrm{abs}}(r)=\frac{6 \pi E(m)}{\lambda} f_{v}(r)$.

In Eq. (4), $\mathrm{K}_{\mathrm{abs}}(r)$ is the absorption coefficient, $\lambda$ is the laser beam wavelength, $r$ is the radial distance from the center of the flame, and $E(m)$ is the function of refractive index of soot particles, $m$, as defined by Eq. (5):

$E(m)=-\operatorname{Im}\left(\frac{m^{2}-1}{m^{2}+2}\right)$.

Employing Abel's inversion to transform Eq. (4), a relationship for the local absorption coefficient and the soot volume fraction can be established as follows:

$f_{v}(r)=-\frac{\lambda}{6 \pi^{2} E(m)} \int_{r}^{R} \frac{d\left[\mathrm{I}(x) / \mathrm{I}_{\mathrm{o}}\right]}{d x} \frac{d x}{\sqrt{x^{2}-r^{2}}}$, 
where $x$ is along the optical path and $R$ is the radius of the flame. The refractive index used for the current measurements is $m=1.57-0.56 i$, which is widely used in the literature [e.g., 94,95]. This refractive index has been validated against a wide range of fuels and flame environments [94-101]. Other refractive index values reported in the literature include $m=$ $1.90-0.55 i[102]$ and $m=1.75-1.03 i[103]$. Using these two refractive index values of [102] and [103], calculations based on Eq. (5) show that the value of $E(m)$ would differ by a factor of 0.74 and 1.436, respectively. In a study on oxygenated ester fuels [104], $m=1.58-$ $0.57 i$ was used. Based on the refractive index value of [104], the value of $E(m)$ would differ by a factor of 1.008. Nevertheless, the soot formation ranking determined by using either of these refractive index values would be unaffected.

\subsection{LII signal calibration}

The calibration for the present LII signal was performed using counterflow non-premixed ethylene and $n$-butanol flames. The fuel stream was composed of a fuel/ $\mathrm{N}_{2}$ mixture with the fuel mole fraction of $X_{F}=0.28$ for the ethylene flame and $X_{F}=0.29$ for the $n$-butanol flame, while the $\mathrm{O}_{2} / \mathrm{N}_{2}$ oxidizer stream for both the flames was maintained at an oxygen mole fraction of $X_{O_{2}}=0.90$. For the experimental conditions, a yellow luminous sooting zone was observed towards the fuel nozzle followed by a thin blue flame towards the oxidizer nozzle.

Figure 3(a) plots the radial profiles of soot volume fraction at five different axial locations (z) from the bottom fuel nozzle for the ethylene flame and Fig. 3(b) shows such profiles at three axial locations for the $n$-butanol flame. In Fig. 3, the solid symbols/black lines represent the LE signals and the hollow symbols/gray lines represent the LII signals. Firstly, the LII signal, averaged over 20 images, was compared with the quantitative measurement of soot volume 
fraction at the 'Calibration Point' indicated in Fig. 3(a), with the comparison made for $z=3.35$ $\mathrm{mm}$, for the ethylene flame. With the similar process for the $n$-butanol flame, the LII signal was also compared with the quantitative measurement of soot volume fraction at the 'Calibration Point' indicated in Fig. 3(b), with the comparison made for $z=4.84 \mathrm{~mm}$. Calibration factors were calculated with these comparisons. The calibration factor values were $3.05 \times 10^{8}$ and $3.11 \times 10^{8}$ for the ethylene and $n$-butanol flames, respectively. The similarity of these two values indicates that the experiments compare well for non-oxygenated (ethylene) and oxygenated (n-butanol) flames. Using the calibration factor for each flame, the quantitative values for the LII signals at other $(r, z)$ locations were then calculated. It can be seen from Fig. 3 for both the ethylene and $n$ butanol flames that the radial distributions of soot volume fractions determined from both the LII and LE techniques compare well for all the other axial locations. Another aspect of comparing the radial distribution is its symmetry, thereby suggesting that the variation in optical properties of soot is deemed insignificant as the soot volume fraction distributions compare well.

With the above-mentioned calibration, the use of LII technique facilitates the mapping of soot volume fraction distribution profiles as shown in Fig. 4 for the ethylene flame. It is seen that the overall soot volume fractions increase from $z=2.99 \mathrm{~mm}$ to $z=3.35 \mathrm{~mm}$ (cf. Fig. 4(a)), and then decrease from $z=3.35 \mathrm{~mm}$ to $z=3.71 \mathrm{~mm}$ (cf. Fig. 4(b)). As such, Fig. 4(a) represents the soot inception and growth zone, while Fig. 4(b) represents the soot oxidation zone. At the onset of soot formation, more soot is formed at the radially outward locations than the center, as shown in Fig. 4(a). This is due to longer residence time in the radially outward locations than the center. Moreover, this higher residence time provides more time to the soot formation and growth process. Figure 4(a) also shows that the amount of soot formed increases while moving upwards (towards the flame), both at the center and radially outward locations. Further moving upwards 
from $z=3.35 \mathrm{~mm}$ to $z=3.47 \mathrm{~mm}$, Fig. 4 (b) shows that although the amount of soot continues to grow near the center, the amount of soot decreases at the radially outward locations. This is due to less availability of fuel in the radially outward direction as it is consumed rapidly and possibly diluted by the shroud flow. Then moving upwards from $z=3.51 \mathrm{~mm}$, the overall soot volume fractions decrease due to oxidation, both at the center and radially outward locations.

Similar trend of soot volume fraction distributions in the counterflow non-premixed configuration as Fig. 4 was also observed for other fuels investigated in this study. However, only the axial variations of soot volume fraction along the centerline will be presented and compared in the following discussions.

\section{Computational specifications}

The counterflow flames were simulated using the OPPDIF module in CHEMKIN-PRO [105], which is based on the plug-flow formulation of Kee et al. [106]. The counterflow flame model includes the GAS-PHASE KINETICS subroutine library and TRANSPORT package subroutines. Although a detailed soot modeling considering soot particle inception, coagulation, and growth, such as in Refs.[107-109], were not incorporated here, the computed spatiallyresolved profiles of soot precursors (e.g., $\mathrm{C}_{2} \mathrm{H}_{2}$ and $\mathrm{C}_{3} \mathrm{H}_{3}$ ) using the literature reaction mechanisms for butane and butanol isomers would still provide insight into the sooting propensity ranking for the fuels of interest. In addition, these literature reaction mechanisms were used to make a comparison of the reaction pathways of fuel breaking and key soot precursors such as $\mathrm{C}_{2} \mathrm{H}_{2}$ and $\mathrm{C}_{3} \mathrm{H}_{3}$.

To simulate butane flames, the chemical kinetic models of USC Mech II [110] and Merchant et al. [31] were used. The USC Mech II [110] consists of 111 species and 784 reactions, and is 
relevant to high-temperature oxidation of hydrogen, carbon monoxide, and $\mathrm{C}_{1}-\mathrm{C}_{4}$ hydrocarbons. The chemical kinetic model of Merchant et al. [31] consists of 372 species and 8723 reactions, and was also used for both butane and butanol flame simulations. Another chemical kinetic model used for simulating counterflow flames of butanol isomers was that of Sarathy et al. [111], consisting of 426 species and 2335 reactions.

\section{Results and Discussion}

4.1 Soot volume fraction results with fuel loading, oxygen level, and strain rate variation In order to assess the molecular structure effects on soot formation in butane and butanol flames, soot volume fraction profiles for these flames were measured and compared in the current nonpremixed counterflow burner facility. The exit temperatures of the fuel and oxidizer nozzles were maintained at $T_{i n}=400 \mathrm{~K}$. Moderately sooting flame conditions were chosen in this study, as the LII measurement technique is not suitable for heavily sooting flames. This is because that under heavily sooting conditions the laser fluence threshold cannot be maintained for the entire measurement domain due to the absorption of the laser power by the soot particles. It is also noted that for lightly sooting flames, the sparse density of soot particles results in weaker LII signal strength, which would not be sensitive enough for the LII measurements. Based on the above considerations, experimental conditions of $X_{F}=0.21-0.29$ and $X_{O_{2}}=0.70-0.90$ for the fuel and oxidizer streams, respectively, were employed.

Table 2 lists the calculated adiabatic flame temperatures $\left(T_{a d}\right)$ for all the tested fuels at varying $X_{F}$ and $X_{\mathrm{O}_{2}}$ using the thermodynamics database of Merchant et al. [31]. While the reaction kinetics of fuel pyrolysis and oxidation, aromatics formation, PAH mass growth and oxidation, and soot chemistry are temperature sensitive, for a given set of $X_{F}$ and $X_{O_{2}}$ the slight differences in $T_{a d}$, within the isomers and between butane and butanol, are not expected to have 
an impact on the soot formation processes in different fuels. In addition, the stoichiometric mixture fractions, $Z_{s t}$, defined as:

$Z_{s t}=\left(1+\frac{Y_{F} W_{O_{2}} v_{O_{2}}}{Y_{O_{2}} W_{F} v_{F}}\right)^{-1}=\left(\frac{X_{O_{2}}}{W_{L} v_{O_{2}}}\right) /\left(\frac{X_{O_{2}}}{W_{L} v_{O_{2}}}+\frac{X_{F}}{W_{0} v_{F}}\right)$

for different mixture conditions are also listed in Table 2. In Eq. (7), $Y_{F}$ is the mass fraction of fuel at the fuel stream boundary, $Y_{\mathrm{O}_{2}}$ is the mass fraction of $\mathrm{O}_{2}$ at the oxidizer stream boundary, $W_{F}$ and $W_{\mathrm{O}_{2}}$ are the molecular weights of fuel and $\mathrm{O}_{2}$, respectively, $v_{\mathrm{O}_{2}}$ and $v_{\mathrm{F}}$ are the stoichiometric coefficients of $\mathrm{O}_{2}$ and fuel, respectively, and $W_{L}$ and $W_{0}$ are the average molecular weights of the mixtures at the oxidizer $(z=L)$ and fuel $(z=0)$ stream boundaries, respectively. In combustion theory, the mixture fraction is a normalized coupling function with the mixture fractions of 0 and 1 defining the oxidizer and fuel stream boundaries, respectively [112]. In the flame sheet limit, combustion is considered to be stoichiometrically concentrated and completed at the mixture fraction value of $Z_{s t}$. For all the mixture compositions investigated herein, $Z_{s t}<0.5$, as shown in Table 2, and hence the "flame sheets" are all situated on the oxidizer side of the stagnation plane. Although $Z_{s t}$ has been shown to have a significant effect on soot formation [113-117], for a given set of $X_{F}$ and $X_{O_{2}}$ the difference in $Z_{s t}$ due to the small differences in molecular weights and stoichiometric coefficients for butane and butanol is not significant. Therefore, when comparing the sooting propensity, the effect of $Z_{s t}$ on the soot volume fraction is not considered in the present study.

Soot formation is a rate-limiting process, and hence it depends on the strain rate that characterizes the residence time experienced by the reactants in the combustion zone of a counterflow non-premixed flame. A higher strain rate implies a shorter residence time experienced by the combustion reactions. In this study, since the nozzle-generated exit flow is plug-like, the global strain rate $(K)$, based on the relation of Seshadri and Williams [118]: 
$K=\frac{2 V_{L}}{L}\left(1+\frac{V_{0} \sqrt{\rho_{0}}}{V_{L} \sqrt{\rho_{L}}}\right)$

is used to represent the strain rate effect. In Eq. (8), $V$ is the bulk velocity at the nozzle exit, $\rho$ is the density, and the subscripts 0 and $L$ represent the fuel $(z=0)$ and oxidizer $(z=L)$ stream boundaries, respectively. Equation (8) also takes the effects of varying density at two boundaries into account.

The soot volume fraction profiles along the centerline of various flames at the experimental conditions of $X_{F}=0.29, X_{O_{2}}=0.90$, and $K=57 \mathrm{~s}^{-1}\left(V_{0}=V_{L}=14.9 \mathrm{~cm} / \mathrm{s}\right)$ are presented and compared in Fig. 5. In Fig. 5(a) the soot profiles for all the fuels are shown with a y-axis scale of $10^{-5}-10^{-4}$, while in Fig. 5(b) these are shown using a y-axis scale of $10^{-7}-10^{-6}$ so that the profiles for $n-$, iso-, and sec-butanol can be more prominent. In general, the soot volume fraction profile can be divided into three zones, namely inception, growth, and oxidation for soot. The soot inception zone exists towards the fuel side, where due to the higher concentrations of soot precursors, initial single ring aromatics formation takes place. Further growth in soot is due to various parallel pathways of soot formation and growth, such as aromatic condensation, hydrogen-abstraction/carbon-addition (HACA), etc. The maximum soot volume fraction in Fig. 5 is attained near $z=4.85 \mathrm{~mm}$ from the fuel nozzle. After the peak, in the soot oxidation zone, there is a decrease in the soot volume fraction along the centerline, as the soot particles are oxidized due to high temperature.

The sooting propensity for counterflow non-premixed flames can be ranked based on the maximum soot volume fraction along the centerline of the flame [104]. As such, the sooting propensities of butane and butanol isomers can be inferred from Fig. 5 as $n$-butane > iso-butane $>$ tert-butanol > $n$-butanol > iso-butanol > sec-butanol. In previous studies of [63,64,119-122], the sooting propensities were defined by the measurements of the incipient soot particles or the 
sooting limits. These studies generally noted a higher sooting tendency for butanols than butanes, as well as a higher sooting tendency for the branched chain isomers than the straight chain isomers. In addition, such observations at the incipient stage were found to be correlated with the tendency of fuel to form soot precursors of acetylene and propargyl. In the current study, sooting propensity is defined by comparing the maximum soot volume fractions in moderately sooting flames involving complex soot growth pathways, such as soot particle nucleation, surface reactions, coagulation, and oxidation [123-129]. Based on the flame configuration (e.g., premixed versus non-premixed combustion or counterflow non-premixed versus coflow flames), the sooting behaviors of fuels may also change [130]. Due to the complexities involved with the soot formation process, the incipient soot formation stage may not be the rate limiting process [131-134], and hence the difference in sooting propensity ranking.

With $X_{O_{2}}=0.90$ and $K \sim 57 \mathrm{~s}^{-1}\left(V_{0}=V_{L}=14.9 \mathrm{~cm} / \mathrm{s}\right)$, Fig. 6 further compares the sooting propensities for butane and butanol isomers by plotting the maximum soot volume fraction along the centerline as a function of $X_{F}$ varying from 0.21 to 0.29 . The error bars are plotted based on twice the standard deviation of the repeated measurements. For all the fuels investigated, it is observed that the maximum soot volume fraction increases as $X_{F}$ is increased, while keeping $X_{O_{2}}$ and $K$ fixed. The increase in the fuel mole fraction increases the amount of soot precursors and hence an increased soot volume fraction. Under the present experimental conditions, the observed sooting propensity ranking remains the same as in Fig. 5; however the slopes for different fuels shown in Figs. 6 vary. Since the butane isomers have higher sooting propensity than butanol isomers, this difference can be attributed to the presence of hydroxyl group (-OH) in butanol isomers. Within the isomers, the sooting propensity differs and that can be attributed to 
the structural differences in isomers. Those molecular structural effects on soot formation will be discussed in due course.

In Fig. 7 the effect of strain rate in the sooting zone for $n$-butanol is shown for $X_{F}=0.29$, $X_{O_{2}}=0.90$, and $K=32-94 \mathrm{~s}^{-1}\left(V_{0}=V_{L}=8.3-24.8 \mathrm{~cm} / \mathrm{s}\right)$, by plotting and comparing the soot volume fraction profiles along the centerline of the flames. As expected, both the sooting zone thickness and the overall soot loading decrease with increasing strain rate due to the reduction in characteristic residence time within the flame. Although not shown here, similar strain rate effects were also observed for other fuels. In Figs. 8(a) and 8(b), the maximum soot volume fractions along the centerline at varying strain rates are shown for the butane and butanol isomers. Again, the experimental conditions were kept at $X_{F}=0.29$ and $X_{O_{2}}=0.90$. It is seen from Figs. 8 that the maximum soot volume fraction decreases with an increase in strain rate for all the fuels. Within the same isomeric class, it is of interest to note that the fuels exhibit disproportionate decrease in maximum soot volume fraction with an increase in strain rate.

Effects of change in oxygen mole fraction in the oxidizer stream on soot formation were also measured. Figure 9 shows and compares the soot volume fraction profiles along the centerline of the $n$-butanol flames for $X_{F}=0.29$ and $X_{O_{2}}=0.70-0.90$. As listed in Table 2, the $Z_{s t}$ values for $X_{O_{2}}$ of $0.70,0.80$, and 0.90 are $0.351,0.379$, and 0.404 , respectively. An increase in $X_{O_{2}}$ leads to an increase in $Z_{s t}$, indicating that the flame shifts away from the oxidizer boundary and towards the stagnation plane. The shift in flame location results in a shift in peak temperature location, which causes the location of maximum soot volume fraction to shift towards the fuel boundary with an increase in $X_{O_{2}}$. In addition, while the overall thicknesses of the sooting zone are comparable because of the same $V_{0}=V_{L}=14.9 \mathrm{~cm} / \mathrm{s}$ and the resulting similar 
strain rate values $\left(K=57-60 \mathrm{~s}^{-1}\right)$, Fig. 9 shows a slight increase of the maximum soot volume fraction with increasing $X_{O_{2}}$.

Figure 10 demonstrates the variations of maximum soot volume fraction along the centerline with $X_{\mathrm{O}_{2}}$ for these isomer fuels. Again, for clarity, in Fig. 10(b) n-, iso-, and sec-butanol are shown which produce soot on a smaller scale and all the isomers are shown in Fig. 10(a). The experimental conditions investigated were for a fixed fuel mole fraction of $X_{F}=0.29$ and varying oxygen mole fractions from 0.70 to 0.90 . For all the fuels with an increase in $X_{O_{2}}$, an increase in the maximum soot volume fraction is observed. As shown in Table 2, the increase in $X_{O_{2}}$ from 0.70 to 0.90 leads to an increase in $T_{a d}$ by $\sim 70 \mathrm{~K}$, thereby facilitating the fuel pyrolysis to increase the amount of soot precursors and promote soot growth mechanisms. In addition, it can be seen from Fig. 10 that the increase in the maximum soot volume fraction for these fuels have a disproportionate response to the change in $X_{\mathrm{O}_{2}}$. Such a fuel specific sooting response to the increase in oxygen mole fraction is expected to be related to different fuel breakdown pathways that are likely caused by the structural effects due to different bond strengths within isomers and the presence of the hydroxyl functional group.

\subsection{Isomeric structure effects on soot formation}

It is established that the soot formation process is dependent on the gas phase chemistry of the fuel, as the soot precursors such as acetylene $\left(\mathrm{C}_{2} \mathrm{H}_{2}\right)$ and propargyl $\left(\mathrm{C}_{3} \mathrm{H}_{3}\right)$ play important roles in soot inception and growth chemistry. In addition, it is widely accepted that soot growth is a complex process of competing reactions between HACA and aromatic condensations. Moreover, the formation of soot precursors depends on the intermediate species formed during the fuel breaking process. 

results of Fig. 6 show that under the investigated conditions butane isomers have a higher sooting tendency than butanol isomers. As the butane isomers do not contain an oxygen atom, the initial decomposition of butane isomers produces intermediates, such as ethyl, propyl, butyl, iso-butyl radicals. The chemical structures for some intermediate species are given in Table 3. Since these intermediate species do not contain an oxygen atom, further decomposition of these intermediate results in butene, propene, and ethylene formation. Butene, propene, and ethylene easily convert into soot precursors such as acetylene and propargyl [64]. Longer chain species like butene and propene are more likely to form propargyl, whereas the shorter chain species like ethylene mostly forms acetylene [64]. On the other hand, due to the presence of a hydroxyl group, a substantial amount of butanols decomposes to form oxygenated intermediate species. These oxygenated intermediates further decompose to form aldehydes and ketones. As compared to the butene, propene, and ethylene, aldehydes and ketones are relatively stable intermediates, thereby producing less soot precursors. From the initial steps of fuel breaking, it can be inferred that the route taken to form soot precursors by butane and butanol isomers would differ. Different fuel breaking pathways have been observed experimentally to lead to differences in incipient soot particle formation [e.g. 63,64].

Strong structural effects within the butane and butanol isomers were observed in the present experiments. Figure 6(a) shows that $n$-butane has higher sooting propensity than iso-butane. Initial fuel breaking of $n$-butane due to direct decomposition and $\mathrm{H}$-abstraction produces methyl, ethyl, propyl, and butyl radicals. On the other hand, initial breaking of iso-butane takes a different route in comparison to $n$-butane, and produces methyl, propyl, and iso-butyl radicals by 
direct decomposition and $\mathrm{H}$-abstraction. Since different initial fuel decomposition pathways are expected to lead to the dissimilar amount of soot precursors, there could be two possible reasons of $n$-butane exhibiting the greater sooting propensity. One of the possibilities is that $n$-butane overall forms substantially larger amount of soot precursors than iso-butane. Another possibility is that either of the HACA or propargyl recombination is highly competitive for $n$-butane. To validate these possibilities further investigations would be required, such as tracking the pathways of PAH growth or direct measurements of acetylene and propargyl precursors.

As per our experimental results in Fig. 6, amongst all the butanol isomers, the sooting propensity ranking from the highest to the least follows tert-butanol, $n$-butanol, iso-butanol, and sec-butanol. A closer look at the initial decomposition pathways for these fuels suggests that these isomers would produce dissimilar amount of soot precursors. One of the pathways of fuel breaking of tert-butanol is through the complex fission to eliminate $\mathrm{H}_{2} \mathrm{O}$, as the hydroxyl group in tert-butanol has nine neighboring hydrogen atoms available to form complex bonds [64]. In the complex fission process the dissociation of fuel occurs by breaking and forming of multiple bonds within the fuel [64]. The result of a complex fission process is to form iso-butene intermediates. Other fuel breaking pathways for tert-butanol are through direct decomposition and H-abstraction to form the methyl, 2-hydroxy-2-methyl-propyl, tert-butoxy, and 1-hydroxy-1methyl-ethyl radicals. Most likely, the pathway of the soot precursor formation for tert-butanol emanates from iso-butene, which converts easily into propargyl [19]. See Table 3 for the chemical structures of some intermediate species. In contrast to tert-butanol, $n$-butanol takes completely different initial fuel breaking pathways. Direct decomposition and $\mathrm{H}$-abstraction are the major initial fuel breaking pathways for $n$-butanol. After the first step of fuel breaking, it produces methyl, ethyl, propyl, 2-hydroxy-ethyl, 3-hydroxy-propyl, 1-hydroxy-methyl, 1-butene, 
3-hydroxy-1-methyl-propyl, 4-hydroxy-butyl, 1-hydroxymethyl-propyl, and 4-hydroxy-butyl. Since iso-butanol has branched structure similar to tert-butanol, the complex fission process for this isomer is one of the fuel breaking possibilities which results in iso-butene formation [64]. However, unlike tert-butanol, iso-butanol has five neighboring hydrogen atoms to form a complex bond so the fuel breaking pathways for these two isomers differ. Apart from complex fission, the fuel breaking pathways for iso-butanol are through direct decomposition and $\mathrm{H}$ abstraction. Initial breaking of iso-butanol through these pathways results in methyl, 2-hydroxy1-methyl-ethyl, 1-methyl-ethyl, 1-hydroxy-methyl, 3-hydroxy-2-methyl-propyl, 2-hydroxy-1methyl-ethyl, and 1-hydroxy-2-methyl-prophyl radicals. Lastly, the availability of one neighboring hydrogen atom provides a complex fission pathway for sec-butanol to form 2-butene and 1-butane intermediates [64]. Other breaking pathways for sec-butanol are also direct decomposition and H-abstraction. These pathways lead to methyl, ethyl, 1-hydroxy-ethyl, 2hydroxy-2-methyl-ethyl, 3-hydroxy-3-methyl-propyl, 2-hydroxy-1-methyl-propyl, 2-hydroxybutyl, and 1-hydroxy-1methyl-propyl radical formation. Hence, from these fuel breaking pathways it is expected that the amount of soot precursors formed by these isomers would not be similar, and the soot formation by these fuels can differ, which has been demonstrated in our experimental results.

\subsection{Fuel decomposition pathway analysis}

Recognizing that the success of a chemical kinetic model in predicting the sooting tendency for a fuel depends on its ability to predict the soot precursors, several literature gas-phase kinetic models were employed to simulate the experimental conditions and their predicted results of soot precursors were compared and discussed in the following. For butane isomers, two available models compared were taken from USC Mech II [110] and Merchant et al. [31]. For $X_{F}=0.29$, 
$X_{O_{2}}=0.90$, and $K=57 \mathrm{~s}^{-1}\left(V_{0}=V_{L}=14.9 \mathrm{~cm} / \mathrm{s}\right)$, computed spatially-resolved mole fraction profiles of acetylene using these two chemical kinetic models are shown and compared in Fig. 11. For $n$ butane the peak acetylene mole fraction for the Merchant model is 0.045 , whereas for the USC Mech II it is 0.050. A comparison for iso-butane shows that the peak acetylene mole fraction predicted by these Merchant and USC Mech II models are 0.038 and 0.049, respectively. Although both of the models predict the higher acetylene mole fraction for $n$-butane than isobutane, the quantitative values have differences between the two models. In addition, the much larger difference in the measured soot loading of butane isomers is not seen to match the difference in the amount of soot precursors produced. This can be understood that as the soot formation being a complex process of various reaction pathways, it may not correlate proportionally with the predicted amount of precursors formed.

Similarly, when the mole fraction profiles of propargyl are compared for $n$-butane, as shown in Fig. 12, the Merchant mechanism predicts a peak value of 0.0012, whereas for the USC Mech II it is 0.00075 . For iso-butane in Fig. 12, the peak propargyl mole fractions predicted by the Merchant and USC Mech II models are 0.0015 and 0.0009, respectively. Although the trend of iso-butane producing more propargyl than $n$-butane holds for both of the models, the amounts predicted differ between the two models. Major initial fuel breaking pathways for the two models are further shown and compared in Fig. 13 for $n$-butane and iso-butane. Overall, the Merchant mechanism predicts that $41.3 \%$ fuel breaking is through direct decomposition of $n$ butane, wherein the USC Mech II shows a $25.5 \%$ contribution from this pathway. The major contribution of fuel breaking pathway for the USC Mech II comes from H-abstraction, which is 72.4\%. Similarly for iso-butane the direct decomposition pathway has $54.2 \%$ and $39.9 \%$ contributions for the Merchant and USC Mech II models, respectively. For iso-butane, H- 
abstraction leads to fuel breaking with $45.7 \%$ contribution for the Merchant model and $60 \%$ contribution for the USC Mech II. Interestingly, it is noticed that although these two models differ in predicting the soot precursors, their predicted profiles of the major species and temperatures match well with each other. It is clear that further investigation is needed to reconcile the discrepancies between the two models, as accurate descriptions of the amount of soot precursors are imperative in soot formation mechanisms.

The chemical kinetic models used for flame simulations of butanol isomers under conditions of $X_{F}=0.29, X_{O_{2}}=0.90$, and $K=57 \mathrm{~s}^{-1}\left(V_{0}=V_{L}=14.9 \mathrm{~cm} / \mathrm{s}\right)$ were taken from Merchant et al. [31] and Sarathy et al. [111]. The spatially-resolved profiles of acetylene predicted by the Merchant and Sarathy models for butanol isomers are shown in Fig. 14. The peak mole fractions of acetylene precursors predicted using the Merchant (Sarathy) model are 0.04 (0.039), 0.037 (0.041), 0.04 (0.042), and 0.025 (0.039) for $n$-butanol, iso-butanol, sec-butanol, and tert-butanol, respectively. A comparison of propargyl precursors predicted by these two models is shown in Fig. 15. The peak mole fractions of propargyl predicted by the Merchant (Sarathy) model are 0.00073 (0.0013), 0.00082 (0.0017), 0.0011 (0.0013), and 0.0022 (0.0027) for $n$-butanol, isobutanol, sec-butanol, and tert-butanol, respectively. Again, both of the models are found to predict dissimilar amounts of precursors formed by butanol isomers and the rankings in terms of peak mole fraction values also differ. A closer look at the fuel breaking steps also illustrates that the two models differ in the major contributions of specific pathways as shown in Fig. 16. The initial breaking step of $n$-butanol shows that the direct decomposition has $40 \%$ and $24.8 \%$ contribution in the Merchant and Sarathy models, respectively. For iso-butanol the direct fuel decomposition has $74 \%$ and $43 \%$ contributions in the Merchant and Sarathy models, respectively. Through the direct decomposition, sec-butanol shows contributions of $70 \%$ and 
$34 \%$ in the Merchant and Sarathy models, respectively. Lastly, in tert-butanol breaking the direct decomposition has $98 \%$ and $82 \%$ contributions in the Merchant and Sarathy models, respectively. The remaining fuel breaking for all the butanol isomers described by both of the models is through $\mathrm{H}$-abstraction reactions.

It can be observed that these models differ in predicting soot precursors and the rankings of butanol isomers in terms of soot precursor formation also differ. From this, it can be inferred that these models would need some improvements/refinements in order to predict the soot precursors so that this information can be used in the subsequent soot modeling. As pointed out by Camacho et al. [63], while the sooting premixed flame behavior at the nucleation stage can be predicted by the soot precursors, the sooting behavior at mass growth stage cannot be directly explained by the species profiles of soot precursors. This could be another reason why no direct correlation between the computed mole fractions of soot precursors and the measured amount of soot formed in the present experimental conditions was observed.

Furthermore, the chemical kinetic models employed here do not include PAH chemistry, and hence the concentrations of other important soot precursors such as benzene, napthalene, phenanthrene, pyrene, and larger ring PAH molecules cannot be simulated to compare with the experimental results on sooting propensity rankings for butane and butanol flames. Reconging the important role of PAHs in soot formation process [135], PAH measurements in moderately sooting flames of butane and butanol isomers are currently in progress in order to better interpret isomeric structure effects on soot formation. 


\section{Conclusions}

Atmospheric-pressure, non-premixed, sooting flames of butane and butanol isomers in a counterflow configuration were investigated. Laser diagnostics techniques were implemented to carry out quantitative measurements of soot volume fraction profiles. Due to the molecular structure effects, the sooting behaviors of fuels within the same isomeric class were found to differ. These differences were linked to different initial fuel breaking pathways pertaining to different $\mathrm{C}-\mathrm{C}, \mathrm{C}-\mathrm{H}$ bond strengths within isomers. The presence of hydroxyl (-OH) group in butanol isomers was noted to affect the sooting behavior, as the butane isomers were found to produce more soot than butanol isomers for the conditions investigated. The effects of fuel mole fraction, oxygen mole fraction, and strain rate on soot formation were also investigated for these fuels. For the conditions studied, the sooting tendency ranking generally follows $n$-butane >isobutane $>$ tert-butanol $>n$-butanol $>$ iso-butanol $>$ sec-butanol. The counterflow non-premixed flames were also simulated using the gas-phase chemical kinetic models available in the literature to compute the spatially-resolved profiles of soot precursors, including acetylene and propargyl. However, the experimentally-observed sooting propensity ranking does not correlate well with the rankings for the computed peak mole fractions of soot precursors. These rankings may not correlate with each other as the soot formation and growth is a non-linear process. In addition, qualitative and quantitative dissimilarities in the computed mole fractions of soot precursors, as well as the differences in the initial fuel breaking steps, predicted by the literature kinetic models are noted. Further chemical kinetic studies are needed to reconcile such discrepancies. 


\section{Acknowledgements}

This material is based upon work supported as part of the Combustion Energy Frontier Research

Center, an Energy Frontier Research Center funded by the U.S. Department of Energy, Office of Science, Office of Basic Energy Sciences under Award Number DE-SC0001198. The work at Beihang University was supported by the Project of National Natural Science Foundation of China, and the Fundamental Research Funds for the Central Universities of China. 


\section{References}

[1] A. Jess, What might be the energy demand and energy mix to reconcile the world's pursuit of welfare and happiness with the necessity to preserve the integrity of the biosphere? Energy Policy 38(8) (2010) 4663-4678.

[2] P.S. Nigam, A. Singh, Production of liquid biofuels from renewable resources, Prog. Energy Combust. Sci. 37(1) (2011) 52-68.

[3] A.L. Demain, Biosolutions to the energy problems, J. Ind. Microbiol. Biotechnol. 36 (3) (2009) 319-332.

[4] N. Barron, D. Brady, G. Love, R. Marchant, P. Nigam, L. McHale, A.P. McHale, Alginate immobilized thermotolerant yeast for conversion of cellulose to ethanol, Prog. Biotechnol. 11 (1996) 379-383.

[5] K. Othmer, Encyclopedia of Chemical Technology, John Wiley and Sons, New York, 4 (1) 1991.

[6] Z. Zhang, Z. Huang, X. Wang, J. Xiang, X. Wang, H. Miao, Measurements of laminar burning velocities and Markstein lengths for methanol-air-nitrogen mixtures at elevated pressures and temperatures, Combust. Flame 155 (3) (2008) 358-368.

[7] S.M. Sarathy, M.J. Thomson, C. Togbé, P. Dagaut, F. Halter, C. Mounaim-Rousselle, An experimental and kinetic modeling study of n-butanol combustion, Combust. Flame 156 (4) (2009) 852-864.

[8] X. Gu, Z. Huang, S. Wu, Q. Li, Laminar burning velocities and flame instabilities of butanol isomers-air mixtures, Combust. Flame 157 (12) (2010) 2318-2325.

[9] P.S. Veloo, Y.L. Wang, F.N. Egolfopoulos, C.K. Westbrook, A comparative experimental and computational study of methanol, ethanol, and n-butanol flames, Combust. Flame 157 (10) (2010) 1989-2004.

[10] J.T. Moss, A.M. Berkowitz, M.A. Oehlschlaeger, J. Biet, V. Warth, P.A. Glaude, An experimental and kinetic modeling study of the oxidation of the four isomers of butanol, J. Phys. Chem. A 112 (2008) 10843-10855.

[11] P.S. Veloo, F.N. Egolfopoulos, Flame propagation of butanol isomers/air mixtures, Proc. Combust. Inst. 33 (2011) 987-993.

[12] H. Jin, Y. Wang, K. Zhang, H. Guo, F. Qi, An experimental study on the formation of polycyclic aromatic hydrocarbons in laminar coflow non-premixed methane/air flames doped with four isomeric butanols, Proc. Combust. Inst. 34 (2013) 779-786.

[13] B. Yang, P. Oßwald, Y. Li, J. Wang, L. Wei, Z. Tian, F. Qi, K. Kohse-Höinghaus, Identification of combustion intermediates in isomeric fuel-rich premixed butanol-oxygen 
flames at low pressure, Combust. Flame 148 (4) (2007)198-209.

[14] R. Grana, A. Frassoldati, T. Faravelli, U. Niemann, E. Ranzi, R. Seiser, R. Cattolica, K. Seshadri, An experimental and kinetic modeling study of combustion of isomers of butanol, Combust. Flame 157 (11) (2010) 2137-2154.

[15] H. Jin, A. Cuoci, A. Frassoldati, T. Faravelli, Y. Wang, Y. Li, F. Qi, Experimental and kinetic modeling study of PAH formation in methane coflow diffusion flames doped with nbutanol, Combust. Flame 161 (3) (2014) 657-670.

[16] H. Ghiassi, P. Toth, J.S. Lighty, Sooting behaviors of $n$-butanol and $n$-dodecane blends, Combust. Flame 161 (3) (2014) 671-679.

[17] F. Wu, C.K. Law, An experimental and mechanistic study on the laminar flame speed, Markstein length and flame chemistry of the butanol isomers, Combust. Flame 160 (12) (2013) 2744-2756.

[18] H. Wang, R.D. Reitz, M. Yao, B. Yang, Q. Jiao, L. Qiu, Development of an n-heptane-nbutanol-PAH mechanism and its application for combustion and soot prediction, Combust. Flame 160 (3) (2013) 504-519.

[19] P. Oßwald, H. Güldenberg, K. Kohse-Höinghaus. B. Yang, T. Yuan, F. Qi, Combustion of butanol isomers-a detailed molecular beam mass spectrometry investigation of their flame chemistry, Combust. Flame 158 (1) (2011) 2-15.

[20] N. Hansen, M.R. Harper, W.H. Green, High-temperature oxidation chemistry of $n$-butanol experiments in low-pressure premixed flames and detailed kinetic modeling, Phys. Chem. Chem. Phys. 13 (2011) 20262-20274.

[21] N. Hansen, S.S. Merchant, M.R. Harper, W.H. Green, The predictive capability of an automatically generated combustion chemistry mechanism: Chemical structures of premixed isobutanol flames, Combust. Flame 160 (11) (2013) 2343-2351.

[22] E.K. Noorani, B. Akih-Kumgeh, J.M. Bergthorson, Comparative high temperature shock tube ignition of C1-C4 primary alcohols, Energy Fuels 24 (2010) 5834-5843.

[23] X. Gu, Z. Huang, Q. Li, C. Tang, Measurements of laminar burning velocities and markstein lengths of $n$-butanol-air premixed mixtures at elevated temperatures and pressures, Energy Fuels 23 (2009) 4900-4907.

[24] X. Gu, Q. Li, Z. Huang, N. Zhang, Measurement of laminar flame speeds and flame stability analysis of tert-butanol-air mixtures at elevated pressures, Energy Convers. Manage. 52 (2011) 3137-3146.

[25] W. Lu, A. P. Kelley, C.K. Law, Nonpremixed ignition, laminar flame propagation, and mechanism reduction of n-butanol, iso-butanol, and methyl butanoate, Proc. Combust. Inst. 33 
(2011) 995-1002.

[26] T.S. Norton, F.L. Dryer, The flow reactor oxidation of C1-C4 alcohols and MTBE, Proc. Combust. Inst. 23 (1991) 179-185.

[27] J.K. Lefkowitz, J.S. Heyne, S.H. Won, S. Dooley, H.H. Kim, F.M. Haas, S. Jahangirian, F.L. Dryer, Y. Ju, A chemical kinetic study of tertiary-butanol in a flow reactor and a counterflow diffusion flame, Combust. Flame 159 (3) (2012) 968-978.

[28] K.M. Van Geem, S. Pyl, G. Marin, M.R. Harper, W.H. Green, Accurate high-temperature reaction networks for alternative fuels: butanol isomers, Ind. Eng. Chem. Res. 49 (21) (2010) 10399-10420.

[29] J. Cai, L. Zhang, J. Yang, Y. Li, L. Zhao, F. Qi, Experimental and kinetic modeling study of tert-butanol combustion at low pressure, Energy 43 (2012) 94-102.

[30] J.H. Cai, L.D. Zhang, F. Zhang, Z.D. Wang, Z.J. Cheng, W.H. Yuan, F. Qi, Experimental and kinetic modeling study of $n$-butanol pyrolysis and combustion, Energy Fuel 26 (9) (2012) $5550-5568$.

[31] S.S. Merchant, E.F. Zanoelo, R.L. Speth, M.R. Harper, K.M. Van Geem, W.H. Green, Combustion and pyrolysis of iso-butanol: Experimental and chemical kinetic modeling study, Combust. Flame 160 (10) (2013) 1907-1929.

[32] I. Stranic, D.P. Chase, J.T. Harmon, S. Yang, D.F. Davidson, R.K. Hanson, Shock tube measurements of ignition delay times for the butanol isomers, Combust. Flame 159 (2) (2012) $516-527$.

[33] G. Black, H. Curran, S. Pichon, J. Simmie, V. Zhukov, Bio-butanol: Combustion properties and detailed chemical kinetic model, Combust. Flame 157 (2) (2010) 363-373. 
[34] K. Yasunaga, T. Mikajiri, S.M. Sarathy, T. Koike, F. Gillespie, T. Nagy, J.M. Simmie, H.J. Curran, A shock tube and chemical kinetic modeling study of the pyrolysis and oxidation of butanols, Combust. Flame 159 (6) (2012) 2009-2027.

[35] I. Stranic, S.H. Pyun, D.F. Davidson, R.K. Hanson, Multi-species measurements in 1butanol pyrolysis behind reflected shock waves, Combust. Flame 159 (11) (2012) 3242-3250.

[36] C.M. Rosado-Reyes, W. Tsang, Shock tube study on the thermal decomposition of $n$ butanol, J. Phys. Chem. A 116 (40) (2012) 9825-9831.

[37] R.D. Cook, D.F. Davidson, R.K. Hanson, Multispecies laser measurements of $n$-butanol pyrolysis behind reflected shock waves, Int. J. Chem. Kinet. 44 (5) (2012) 303-311.

[38] S. Vranckx, K.A. Heufer, C. Lee, H. Olivier, L. Schill, W.A. Kopp, K. Leonhard, C.A. Taatjes, R.X. Fernandes, Role of peroxy chemistry in the high-pressure ignition of $n$-butanol Experiments and detailed kinetic modelling, Combust. Flame 158 (8) (2011) 1444-1455.

[39] K.A. Heufer, R.X. Fernandes, H. Olivier, J. Beeckmann, O. Rohl, N. Peters, Shock tube investigations of ignition delays of n-butanol at elevated pressures between 770 and $1250 \mathrm{~K}$, Proc. Combust. Inst. 33 (1) (2011) 359-366.

[40] Y. Zhu, D.F. Davidson, R.K. Hanson, 1-Butanol ignition delay times at low temperatures: An application of the constrained-reaction-volume strategy, Combust. Flame 161 (3) (2014) 634-643.

[41] J. Zhang, S. Niu, Y. Zhang, C. Tang, X. Jiang, E. Hu, Z. Huang, Experimental and modeling study of the auto-ignition of $n$-heptane/ $n$-butanol mixtures, Combust. Flame 160 (1) (2013) 3139.

[42] B.W. Weber, K. Kumar, Y. Zhang, C.J. Sung, Autoignition of $n$-butanol at elevated pressure and low-to-intermediate temperature, Combust. Flame 158 (5) (2011) 809-819.

[43] B.W. Weber, C.J. Sung, Comparative autoignition trends in butanol isomers at elevated pressure, Energy Fuels 27 (3) (2013) 1688-1698.

[44] Y. Zheng, W. Yue, Y. Xin, Q. Yong, L. XingCai, H. Zhen, Autoignition of butanol isomers/n-heptane blend fuels on a rapid compression machine in $\mathrm{N}_{2} / \mathrm{O}_{2} / \mathrm{Ar}$ mixtures, Sci. China. Tech. Sci. 57 (2014) 461-470.

[45] K. Kumar, Y. Zhang, C.J. Sung, W.J. Pitz, Autoignition response of $n$-butanol and its blends with primary reference fuel constituents of gasoline, Combust. Flame 162(6) (2015) 2466-2479.

[46] J.A. Barnard, The pyrolysis of $n$-butanol, Trans. Faraday Soc. 53 (1957) 1423-1430.

[47] J.A. Barnard, The pyrolysis of tert.-butanol, Trans. Faraday Soc. 55 (1959) 947-951.

[48] W. Tsang, Thermal decomposition of some tert-butyl compounds at elevated temperatures, 


\author{
J. Chem. Phys. 40 (1964) 1498-1505.
}

[49] D. Lewis, M. Keil, S. Michael, M. Sarr, Gas phase thermal decomposition of tert-butyl alcohol, J. Am. Chem. Soc. 96 (1974) 4398-4404.

[50] T. Choudhury, M. Lin, C. Lin, W. Sanders, Thermal decomposition of $t$-butyl alcohol in shock waves, Combust. Sci. Technol. 71 (1990) 219-232.

[51] P. Dagaut, S.M. Sarathy, M.J. Thomson, A chemical kinetic study of $n$-butanol oxidation at elevated pressure in a jet stirred reactor, Proc. Combust. Inst. 32 (2009) 229-237.

[52] C. Togbé, A. Mzé-Ahmed, P. Dagaut, Kinetics of oxidation of 2-butanol and iso-butanol in a jet-stirred reactor: Experimental study and modeling investigation, Energy Fuels 24 (2010) $5244-5256$.

[53] P. Saisirirat, C. Togbe, S. Chanchaona, F. Foucher, C. Mounaim-Rousselle, P. Dagaut, Auto-ignition and combustion characteristics in HCCI and JSR using 1 -butanol $/ n$-heptane and ethanol/ $n$-heptane blends, Proc. Combust. Inst. 33 (2) (2011) 3007-3014.

[54] C. Togbé, G. Dayma, A. Mzé-Ahmed, P. Dagaut, Experimental and modeling study of the kinetics of oxidation of simple biodiesel-biobutanol surrogates: Methyl octanoate-butanol mixtures, Energy Fuels 24 (7) (2010) 3906-3916.

[55] P. Dagaut, C. Togbé, Experimental and modeling study of the kinetics of oxidation of butanol- $n$-heptane mixtures in a jet-stirred reactor, Energy Fuels 23 (7) (2009) 3527-3535.

[56] P. Dagaut, C. Togbé, Oxidation kinetics of butanol-gasoline surrogate mixtures in a jetstirred reactor: Experimental and modeling study, Fuel 87 (15-16) (2008) 3313-3321.

[57] F.N. Alasfour, Butanol-a single cylinder engine study: engine performance, Int. J. Energy Res. 21 (1) (1997) 21-30.

[58] F.N. Alasfour, Butanol-A single-cylinder engine study: availability analysis, Appl. Therm. Eng. 17 (1997) 537-549.

[59] M. Gautam, D.W. Martin, D. Carder, Combustion characteristics of higher-alcohol/gasoline blends, Proc. Inst. Mech. Eng. 214 A (2000) 497-511.

[60] M. Gautam, D. M. Martin, Emissions characteristics of higher alcohol/gasoline blends, Proc. Inst. Mech. Eng. 214 A (2000) 165-182.

[61] Y. Yacoub, R. Bata, M. Gautam, The performance and emission characteristics of C1-C5 alcohol-gasoline blends with matched oxygen content in a single-cylinder spark ignition engine, Proc. Inst. Mech. Eng. 212 (1998) 363-379.

[62] T.K. Bhattacharya, S. Chatterjee, T.N. Mishra, Performance of a constant speed CI engine on alcohol-diesel micro emulsion, Appl. Eng. Agric. 20 (3) (2004) 253-257. 
[63] J. Camacho, S. Lieb, H. Wang, Evolution of size distribution of nascent soot in $n$-and $i$ butanol flames, Proc. Combust. Inst. 34 (1) (2013) 1853-1860.

[64] C.S. McEnally, L. D. Pfefferle, Fuel decomposition and hydrocarbon growth processes for oxygenated hydrocarbons: butyl alcohols, Proc. Combust. Inst. 30 (1) (2005) 1363-1370.

[65] P.H. McMurry, A review of atmospheric aerosol measurements, Atmos. Environ. 34(12-14) (2000) 1959-1999.

[66] X. Hui, A.K. Das, K. Kumar, C.J. Sung, S. Dooley, F.L. Dryer, Laminar flame speeds and extinction stretch rates of selected aromatic hydrocarbons, Fuel 97 (2012) 695-702.

[67] X. Hui, C.J. Sung, Laminar flame speeds of transportation-relevant hydrocarbons and jet fuels at elevated temperatures and pressures, Fuel 109 (2013) 191-200.

[68] M. Hofmann, W.G. Bessler, C. Schulz, H. Jander, Laser-induced incandescence for soot diagnostics at high pressures, Appl. Opt. 42 (2003) 2052-2062.

[69] F. Liu, K.J. Daun, D.R. Snelling, G.J. Smallwood, Heat conduction from a spherical nanoparticle: status of modeling heat conduction in laser-induced incandescence, Appl. Phys. B 83 (2006) 355-382.

[70] A. Boiarciuc, F. Foucher, C. Mounaim-Rousselle, Soot volume fractions and primary particle size estimate by means of the simultaneous two-color-time-resolved and 2D laserinduced incandescence, Appl. Phys. B 83 (2006) 413-421.

[71] T. Dreier, B. Bougie, N. Dam, T. Gerber, Modeling of time-resolved laser-induced incandescence transients for particle sizing in high-pressure spray combustion environments: a comparative study, Appl. Phys. B 83 (2006) 403-411.

[72] T. Ni, S.B. Gupta, R.J. Santoro, Suppression of soot formation in ethene laminar diffusion flames by chemical additives, Symp. (Int.) Combust. 25 (1994) 585-592.

[73] R.L. Vander Wal, K.A. Jensen, Laser-induced incandescence: excitation intensity, Appl. Opt. 37 (1998) 1607-1616.

[74] M. Braun-Unkhoff, A. Chrysostomou, E. Gutheil, R. Lückerath, W. Sticker, Experimental and numerical study on soot formation in laminar high pressure flames, Proc. Combust. Inst. 27 (1998) 1565-1572.

[75] O. Angrill, H. Geitlingea, T. Streibel, R. Suntz, H. Bockhorn, Influence of exhaust gas recirculation on soot formation in diffusion flames, Proc. Combust. Inst. 28 (2000) 2643-2649.

[76] F. Cignoli, S. De Iuliis, V. Manta, G. Zizak, Two-dimensional two-wavelength emission technique for soot diagnostics, Appl. Opt. 40 (30) (2001) 5370-5378.

[77] V. Krüger, C. Wahl, R. Hadef, K.P. Geigle, W. Stricker, M. Aigner, Comparison of laser- 
induced incandescence method with scanning mobility particle sizer technique: the influence of probe sampling and laser heating to soot particle size distribution, Meas. Sci. Technol. 16 (2005) $1477-1486$.

[78] H. Bockhorn, H. Geitlinger, B. Jungfleisch, T. Lehre, A. Schön, T. Streibel, R. Suntz, Progress in characterization of soot formation by optical methods, Phys. Chem. Chem. Phys. 4 (2002) 3780-3793.

[79] J. Park, H.R. Ryoo, H.S. Chun, S. Song, J.W. Hahn, K.M. Chun, A study on time resolved laser induced incandescence analysis method for the measurements of primary particle size in diesel exhaust, JSME Int. J. Series B 49 (2006) 1-7.

[80] A.V. Filippov, M.W. Markus, P. Roth, In-situ characterization of ultrafine particles by laserinduced incandescence: sizing and particle structure determination, J. Aerosol Sci. 30 (1999) 7187.

[81] F. Cignoli, S. Benecchi, G. Zizak, Time-delayed detection of laser-induced incandescence for the two-dimensional visualization of soot in flames, Appl. Opt. 33 (24) (1994) 5778-5782.

[82] T. Ni, J.A. Pinson, S. Gupta, R.J. Santoro, Two-dimensional imaging of soot volume fraction by the use of laser-induced incandescence, Appl. Opt. 34 (30) (1995) 7083-7091.

[83] C.R. Shaddix, K.C. Smyth, Laser-induced incandescence measurements of soot production in steady and flickering methane, propane, and ethylene diffusion flames, Combust. Flame 107 (4) (1996) 418- 452.

[84] B. Quay, T.W. Lee, T. Ni, R.J. Santoro, Spatially resolved measurements of soot volume fraction uusing laser-induced incandescence, Combust. Flame 97 (3) (1994) 384-392.

[85] C.R. Shaddix, J.E. Harrington, K.C. Smyth, Quantitative measurements of enhanced soot production in a flickering methane/air diffusion flame, Combust. Flame 99 (1994) 723-732.

[86] R.L. Vander Wal, K.J. Weiland, Laser-induced incandescence: development and characterization toward a measurement of soot-volume fraction, Appl. Phys. B 59 (1994) 445452 .

[87] C.J. Dasch, Continuous-wave probe laser investigation of laser vaporization of small soot particles in a flame, Appl. Opt. 23 (13) (1984) 2209-2215.

[88] R.J. Santoro, C.R. Shaddix, Applied Combustion Diagnostics, Taylor and Francis, New York, 2000, pp. 252-286. 
[89] S. Will, S. Schraml, K. Bader, A. Leipertz, Performance characteristics of soot primary particle size measurements by time-resolved laser-induced incandescence, Appl. Opt. 37 (24) (1998) 5647-5658.

[90] L.A. Melton, Soot diagnostics based on laser heating, Appl. Opt. 23(13) (1984) 2201-2208.

[91] S. Bejaoui, R. Lemaire, P. Desgroux, E. Therssen, Experimental study of the $E(m, \lambda) / E(m, 1064)$ ratio as a function of wavelength, fuel type, height above the burner and temperature, App. Phys. B 116 (2) (2014) 313-323.

[92] C.A.J. Leermakers, M.P.B. Musculus, In-cylinder soot precursor growth in a lowtemperature combustion diesel engine: Laser-induced fluorescence of polycyclic aromatic hydrocarbons, Proc. Comb. Inst. 35(3) (2015) 3079-3086.

[93] C. J. Dasch, One-dimensional tomography: a comparison of Abel, onion-peeling, and filtered backprojection methods, Appl. Opt. 31(8) (1992) 1146-1152.

[94] K.C. Smyth, C.R. Shaddix, The elusive history of $m \sim=1.57-0.56 i$ for the refractive index of soot, Combust. Flame 107 (3) (1996) 314-320.

[95] W.H. Dalzell, A.F. Sarofim, Optical constants of soot and their application to heat-flux calculations, J. Heat Transfer 91 (1) (1969) 100-104.

[96] C.E. Batten, Spectral optical constants of soots from polarized angular reflectance measurements, Appl. Opt. 24 (8) (1985) 1193-1199.

[97] J. Mullins, A. Williams, The optical properties of soot: a comparison between experimental and theoretical values, Fuel 66 (2) (1987) 277-280.

[98] T.T. Charalampopoulos, J.D. Felske, Refractive indices of soot particles deduced from insitu laser light scattering measurements, Combust. Flame 68 (1987) 283-294.

[99] T.T. Charalampopoulos, H. Chang, In situ optical properties of soot particles in the wavelength range from $340 \mathrm{~nm}$ to $600 \mathrm{~nm}$, Combust. Sci. Technol. 59 (1988) 401-421.

[100] T.T. Charalampopoulos, H. Chang, B. Stagg, The effects of temperature and composition on the complex refractive index of flame soot, Fuel 68 (9) (1989) 1173-1179.

[101] H. Chang, T.T. Charalampopoulos, Determination of the wavelength dependence of the refractive indices of flame soot, Proc. R. Soc. London, Ser. A 430 (1990) 577-591.

[102] S.C. Lee, C.L. Tien, Optical constants of soot in hydrocarbon flames, Proc. Combust. Inst. 18 (1981) 1159-1166. 
[103] T.C. Williams, C.R. Shaddix, K.A. Jensen, J.M. Suo-Anttila, Measurement of the dimensionless extinction coefficient of soot within laminar diffusion flames, Int. J. Heat Mass Tran. 50 (7-8) (2007) 1616-1630.

[104] Q. Feng, A. Jalali, A.M. Fincham, Y.L. Wang, T.T. Tsotsis, F.N. Egolfopoulos, Soot formation in flames of model biodiesel fuels, Combust. Flame 159 (2012)1876-1893.

[105] in: CHEMKIN-PRO, Reaction Design: San Diego, 2011.

[106] R.J. Kee, J.A. Miller, G.H. Evans, G.D. Lewis, A computationalm of the structure and the extinction of strained, opposed flow, premixed methane-air flame, Symp. (Int.) Combust. 22 (1988) 1479-1494.

[107] M. Schenk, N. Hansen, H. Vieker, A. Beyer, A. Gölzhäuser, K. Kohse-Höinghaus, PAH formation and soot morphology in flames of $\mathrm{C}_{4}$ fuels, Proc. Combust. Inst. 35(2) (2015) 17611769.

[108] M. Frenklach, Reaction mechanism of soot formation in flames, Phys. Chem. Chem. Phys. 4 (2002) 2028-2037.

[109] H. Wang, M. Frenklach, A detailed kinetic modeling study of aromatics formation in laminar premixed acetylene and ethylene flames, Combust. Flame 110 (1-2) (1997) 173-221.

[110] H. Wang, X. You, A.V. Joshi, S.G. Davis, A. Laskin, F.N. Egolfopoulos, C.K. Law, USC Mech Version II. High-Temperature Combustion Reaction Model of H2/CO/C1-C4 Compounds. http://ignis.usc.edu/USC_Mech_II.htm, May 2007.

[111] S.M. Sarathy, S. Vranckx, K. Yasunaga, M. Mehl, P. Oßwald, W.K. Metcalfe, C.K. Westbrook, W.J. Pitz, K. Kohse-Höinghaus, R.X. Fernandes, H.J. Curran, A comprehensive chemical kinetic combustion model for the four butanol isomers, Combust. Flame 159 (6) (2012) 2028-2055.

[112] F.A. Williams, Combustion Theory, Addison-Wesley, 1985.

[113] J. Du, R.L. Axelbaum, The effect of flame structure on soot-particle inception in diffusion flames, Combust. Flame 100 (3) (1995) 367-375.

[114] J. Du, R.L. Axelbaum, The effects of flame structure on extinction of $\mathrm{CH}_{4}-\mathrm{O}_{2}-\mathrm{N}_{2}$ diffusion flames, Symp. (Int.) Combust. 26 (1996) 1137-1142.

[115] B.H. Chao, S. Liu, R.L. Axelbaum, On soot inception in nonpremixed flames and the effects of flame structure, Comb. Sci. Tech. 138 (1998) 105-135. 
[116] P.B. Sunderland, R.L. Axelbaum, D.L. Urban, B.H. Chao, S. Liu, Effects of structure and hydrodynamics on the sooting behavior of spherical microgravity diffusion flames, Combust. Flame 132 (1-2) (2003) 25-33.

[117] C.J. Sung, J.B. Liu, C.K. Law, Structural response of counterflow diffusion flames to strain rate variations, Combust. Flame 102 (1995) 481-492.

[118] K. Seshadri, F.A. Williams, Laminar flow between parallel plates with injection of a reactant at high reynolds number, Int. J. Heat Mass Transf. 21 (1978) 251-253.

[119] Y. Wang, S.H. Chung, Effect of strain rate on sooting limits in counterflow diffusion flames of gaseous hydrocarbon fuels: Sooting temperature index and sooting sensitivity index, Combust. Flame 161 (2014) 1224-1234.

[120] C.S. McEnally, L. D. Pfefferle, Sooting tendencies of oxygenated hydrocarbons in laboratory-scale flames, Environ. Sci. Technol. 45 (2011) 2498-2503.

[121] A.E. Karataş, M. Commodo, Ö.L. Gülder, Soot formation in co- and counter-flow laminar diffusion flames of binary mixtures of ethylene and butane isomers and synergistic effects, Energ. Fuels 24 (2010) 4912-4918.

[122] R. Lemairea, D. Lapalmea, P. Seers, Analysis of the sooting propensity of C-4 and C-5 oxygenates: Comparison of sooting indexes issued from laser-based experiments and group additivity approaches, Combust. Flame, 162(9) (2015) 3140-3155.

[123] M. Frenklach, D.W. Clary, W.C. Gardiner, S.E. Stein, Effect of fuel structure on pathways to soot, Proc. Combust. Inst. 21 (1986) 1067-1076.

[124] M. Frenklach, D.W. Clary, T. Yuan, W.C. Gardiner, S.E. Stein, Mechanism of soot formation in acetylene-oxygen mixtures, Combust. Sci. Technol. 50 (1986) 79-115.

[125] M. Frenklach, J. Warnatz, Detailed modeling of PAH profiles in a sooting low-pressure acetylene flame, Combust. Sci. Technol. 51 (1987) 265-283.

[126] M. Frenklach, T. Yuan, M. K. Ramachandra, Soot formation in binary hydrocarbon mixtures, Energ. Fuels 2 (1988) 462-480.

[127] M. Frenklach, D.W. Clary, W.C. Gardiner, S.E. Stein, Detailed kinetic modeling of soot formation in shock-tube pyrolysis of acetylene, Proc. Combust. Inst. 20 (1985) 887-901.

[128] M. Frenklach, H. Wang, Soot Formation in Combustion, in: Mechanisms and Models, Springer-Verlag, Heidelberg, 1994, pp. 165-189.

[129] R.D. Kern, K. Xie, Shock tube studies of gas phase reactions preceding the soot formation process, Prog. Energ. Combust. 17 (1991) 191-210.

[130] I. Glassman, R.A. Yetter, N.G. Glumac, Environmental combustion considerations, 
in:Combustion, 5th Edition, Academic Press, 2014, pp. 393-472.

[131] S.E. Stein, J.A. Walker, M.M. Suryan, A. Fahr, A new path to benzene in flames, Proc. Combust. Symp. 23 (1991) 85-91.

[132] C.F. Melius, J.A. Miller, E.M. Evleth, Unimolecular reaction mechanisms involving $\mathrm{C}_{3} \mathrm{H}_{4}$, $\mathrm{C}_{4} \mathrm{H}_{4}$, and $\mathrm{C}_{6} \mathrm{H}_{6}$ hydrocarbon species, Symp. (Int.) Combust. 24 (1992) 621-628.

[133] M.B. Colket, R.J. Hall, Soot Formation in Combustion,:in Mechanisms and Models, Springer-Verlag, Heidelberg, 1994, pp. 442-468.

[134] P.R. Westmoreland, A.M. Dean, J.B. Howard, J.P. Longwell, Forming benzene in flames by chemically activated isomerization,J. Phys. Chem. 93 (1989) 8171-8180.

[135] C.S. McEnally, L.D. Pfefferle, B. Atakan, K. Kohse-Höinghaus, Studies of aromatic hydrocarbon formation mechanisms in flames: Progress towards closing the fuel gap, Prog. Energ. Combust. 32 (2006) 247-294. 


\section{List of Figures}

Figure 1 Temporal profile of LII signal obtained for an ethylene flame. Normalization is based on the maximum LII signal.

Figure 2 Fluence dependence of normalized integrated LII signal measured for an ethylene flame.

Figure 3 Soot volume fraction profile comparison of LII and LE measurements for (a) a counterflow ethylene flame at five different heights and (b) a counterflow $n$-butanol flame at three different heights, where $\mathrm{z}$ represents the distance from the fuel nozzle. Solid symbols/black lines for LE measurements and hollow symbols/gray lines for LII measurements.

Figure 4 Soot volume fraction distribution in a counterflow ethylene flame: (a) soot formation and growth zone (b) soot decomposition and oxidation zone, where $\mathrm{z}$ represents the distance from the fuel nozzle.

Figure 5 Spatial profiles of soot volume fraction measurements along the centerline for butane and butanol isomers: (a) all the butane and butanol isomers (b) $n$-butanol, iso-butanol, and sec-butanol isomers on an appropriate scale. Conditions: $X_{F}=0.29, X_{O_{2}}=0.90$, and $K=57 \mathrm{~s}^{-1}$.

Figure 6 Maximum soot volume fraction measurements along the centerline for varying fuel mole fractions: (a) all the butane and butanol isomers (b) $n$-butanol, iso-butanol, and sec-butanol isomers on an appropriate scale. Conditions: $X_{O_{2}}=0.90$ and $K \sim 57 \mathrm{~s}^{-1}$. Lines are connected to guide the discernment.

Figure 7 Strain rate effect on soot volume fraction profile along the centerline for $n$-butanol flames. Conditions: $X_{F}=0.29$ and $X_{O_{2}}=0.90$.

Figure 8 Strain rate effect on maximum soot volume fraction along the centerline for butane and butanol isomers: (a) all the butane and butanol isomers (b) $n$-butanol, iso-butanol, and sec-butanol isomers on an appropriate scale. Conditions: $X_{F}=0.29$ and $X_{O_{2}}=0.90$. Lines are connected to guide the discernment.

Figure 9 Oxygen mole fraction effect on soot volume fraction profile along the centerline for $n$-butanol flames with $X_{F}=0.29$.

Figure 10 Oxygen mole fraction effect on maximum soot volume fraction along the centerline 


\section{List of Tables}

Table 1 Chemical structures of butane and butanol isomers.

Table 2 Calculated adiabatic flame temperatures $\left(T_{a d}\right)$ and stoichiometric mixture fractions $\left(Z_{s t}\right)$ for the mixture conditions investigated in the present study.

Table 3 Chemical structures of some intermediate species during initial fuel breaking processes. 


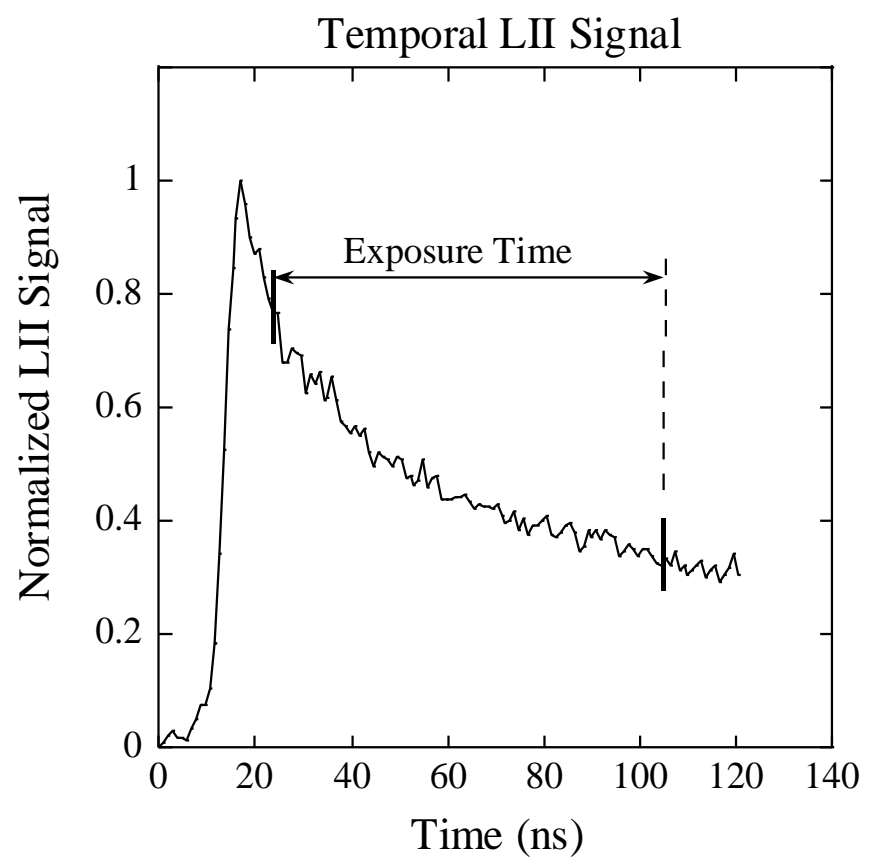

Figure 1 


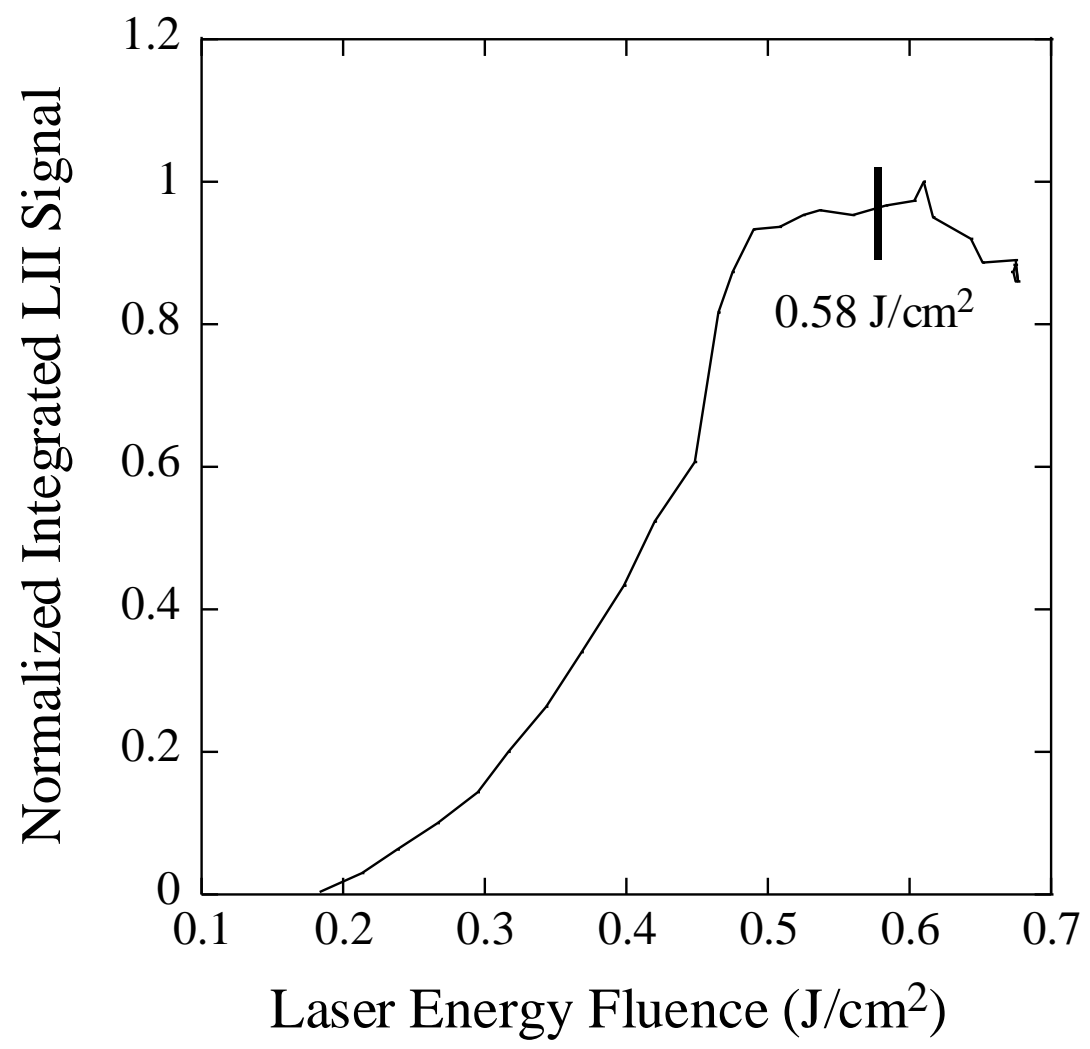

Figure 2 

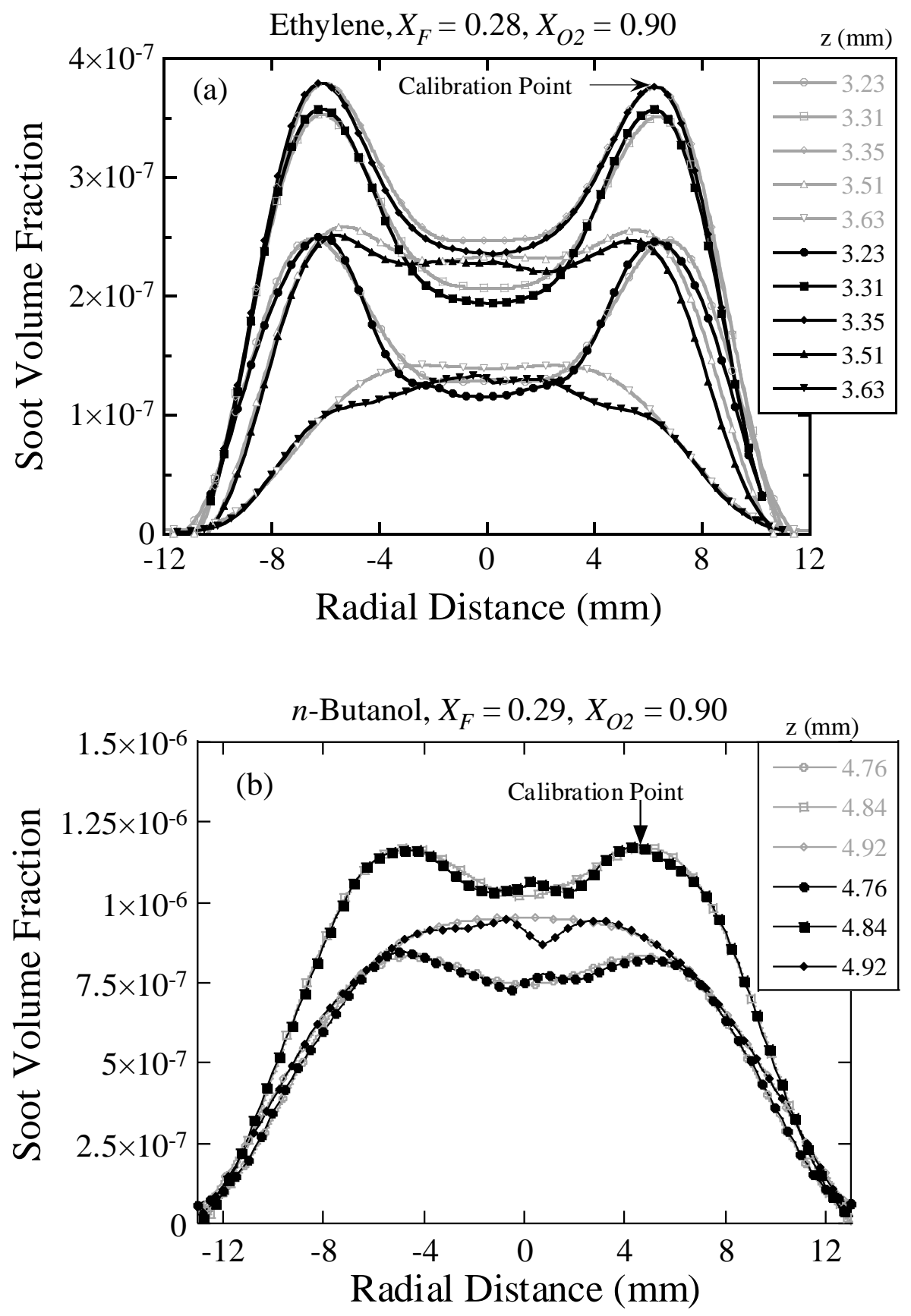

Figure 3 

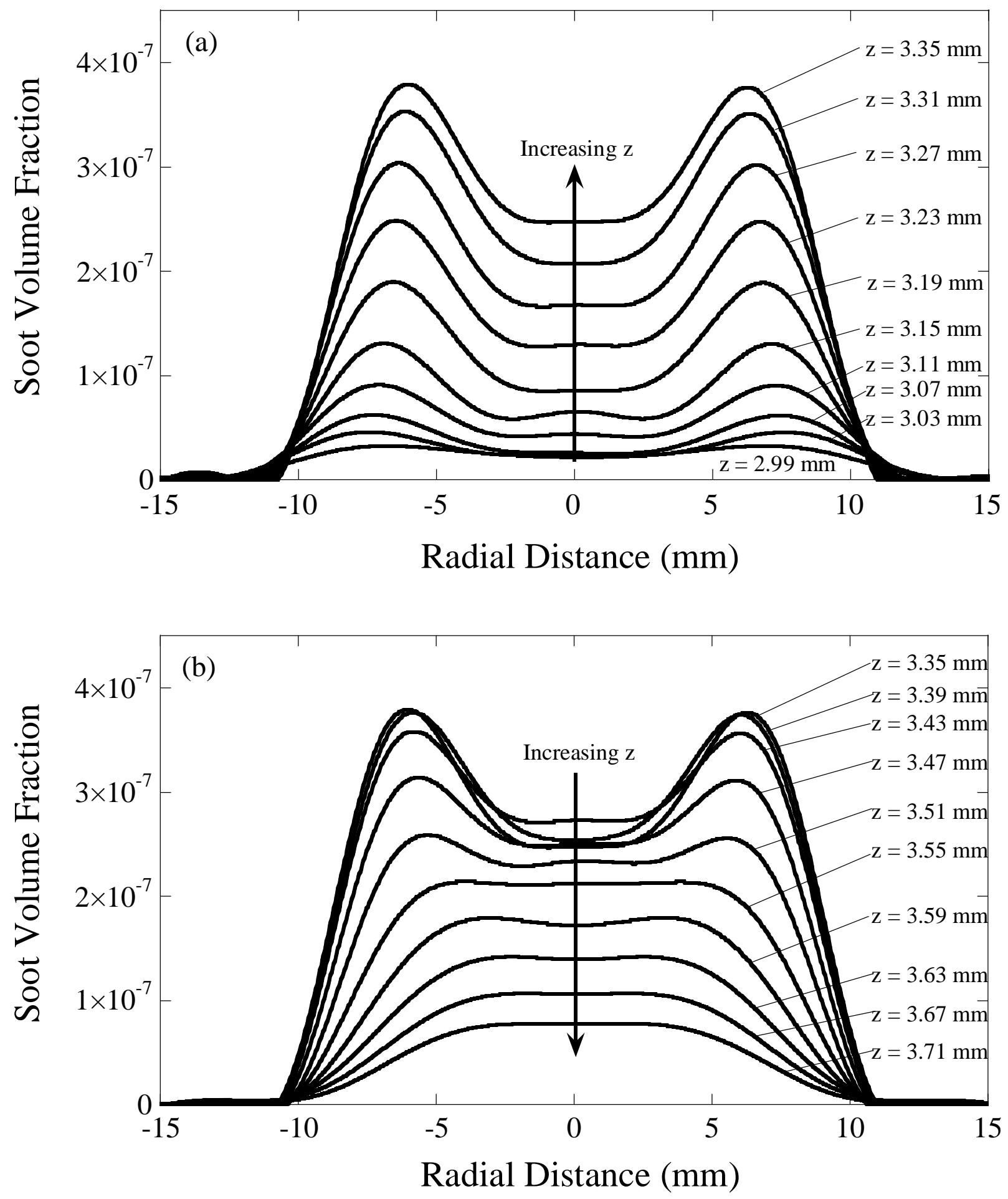

Figure 4 

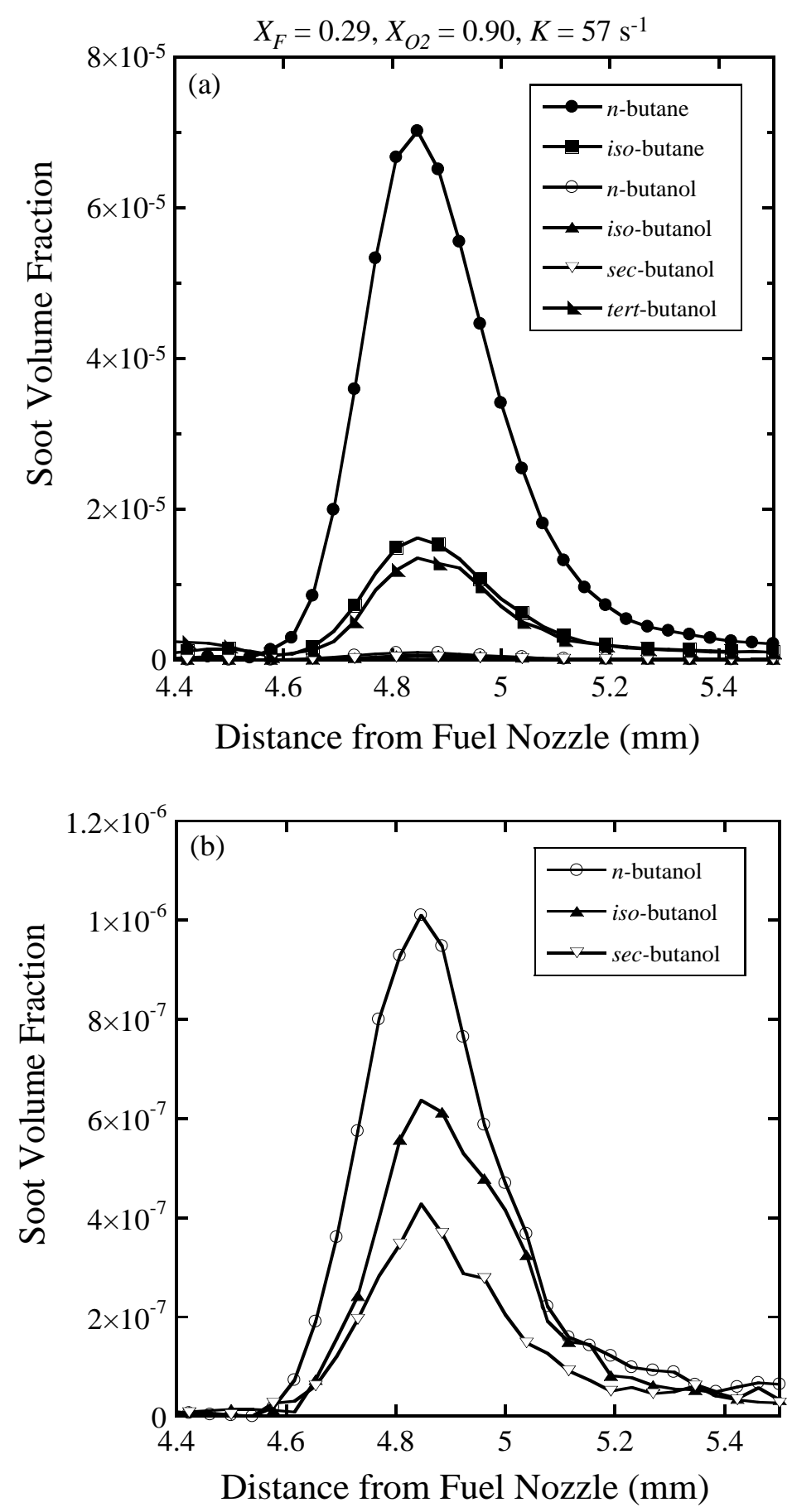

Figure 5 

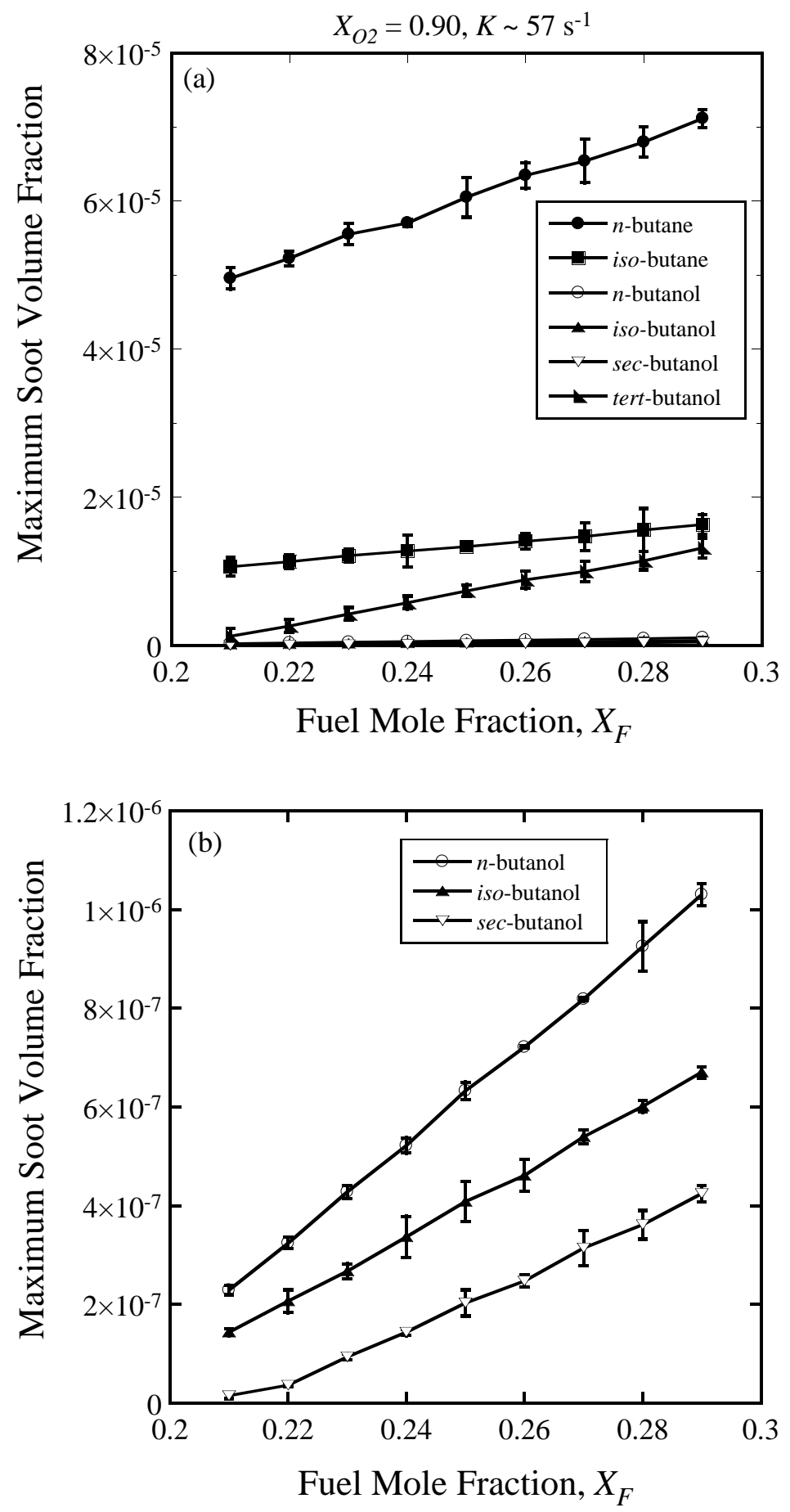

Figure 6 


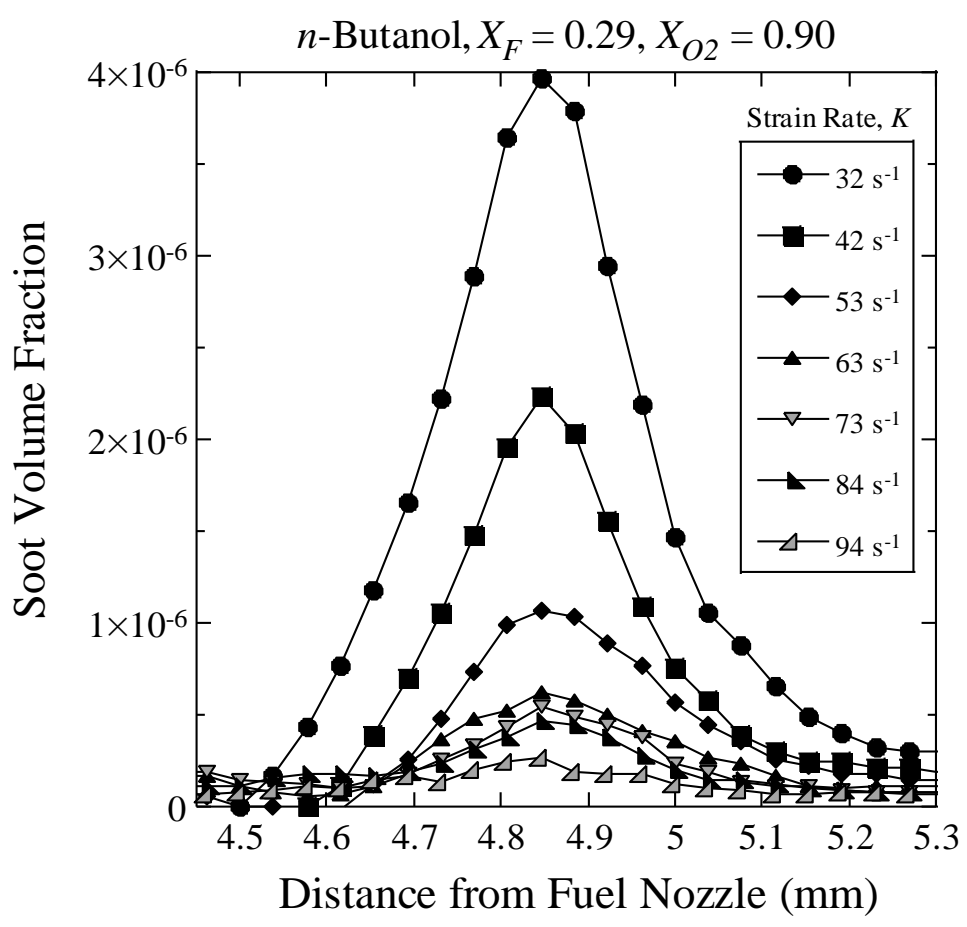

Figure 7 

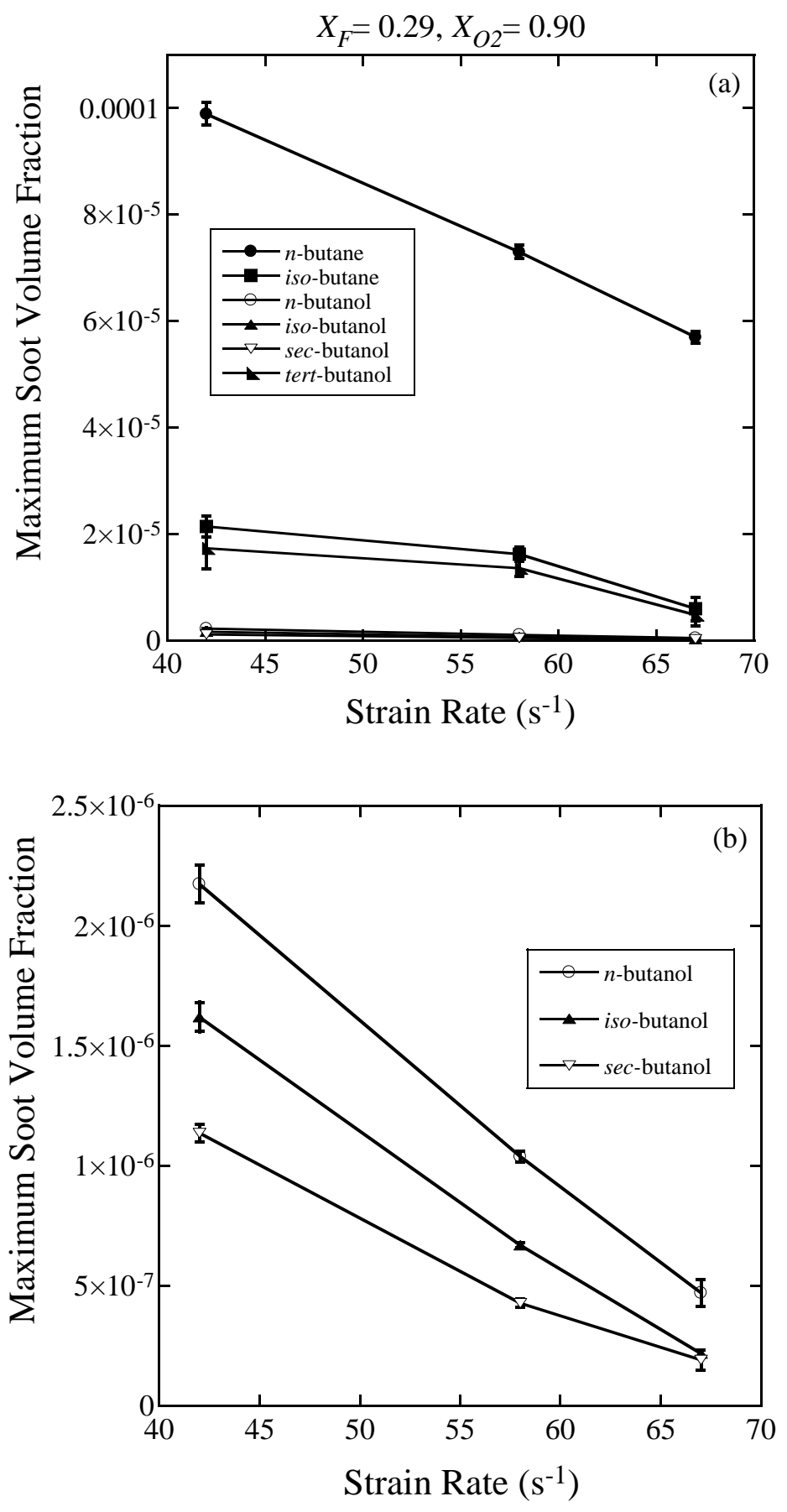

Figure 8 


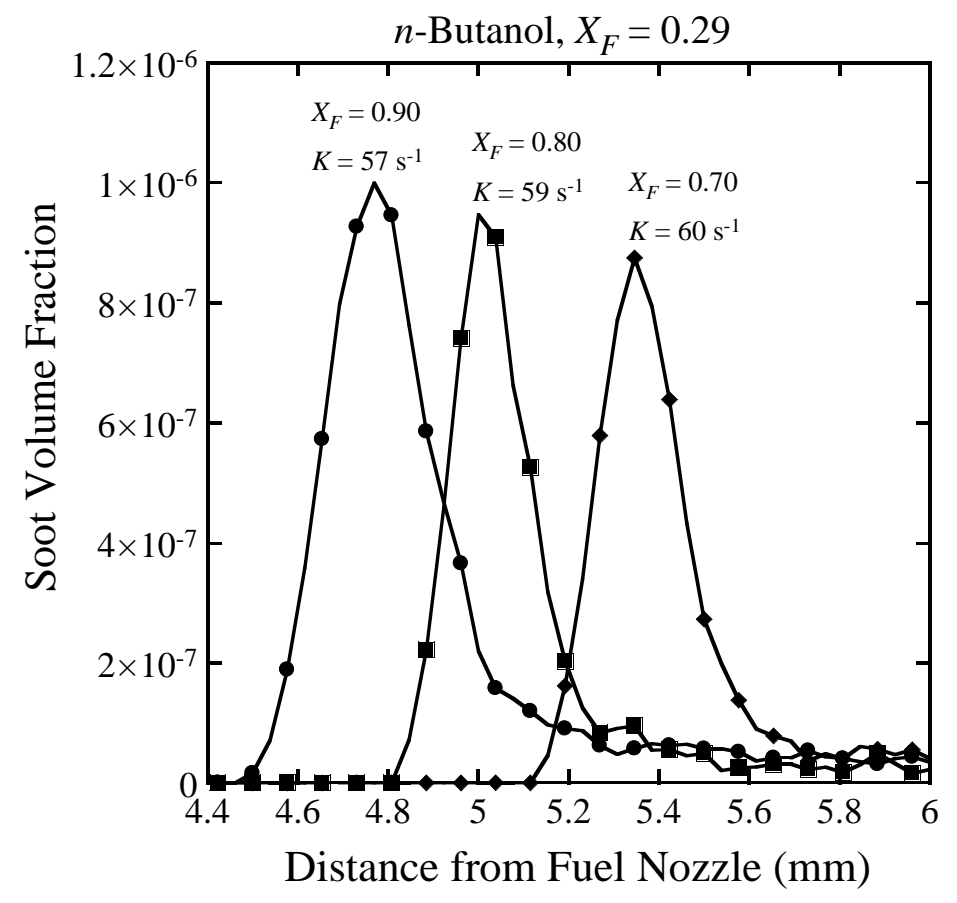

Figure 9 

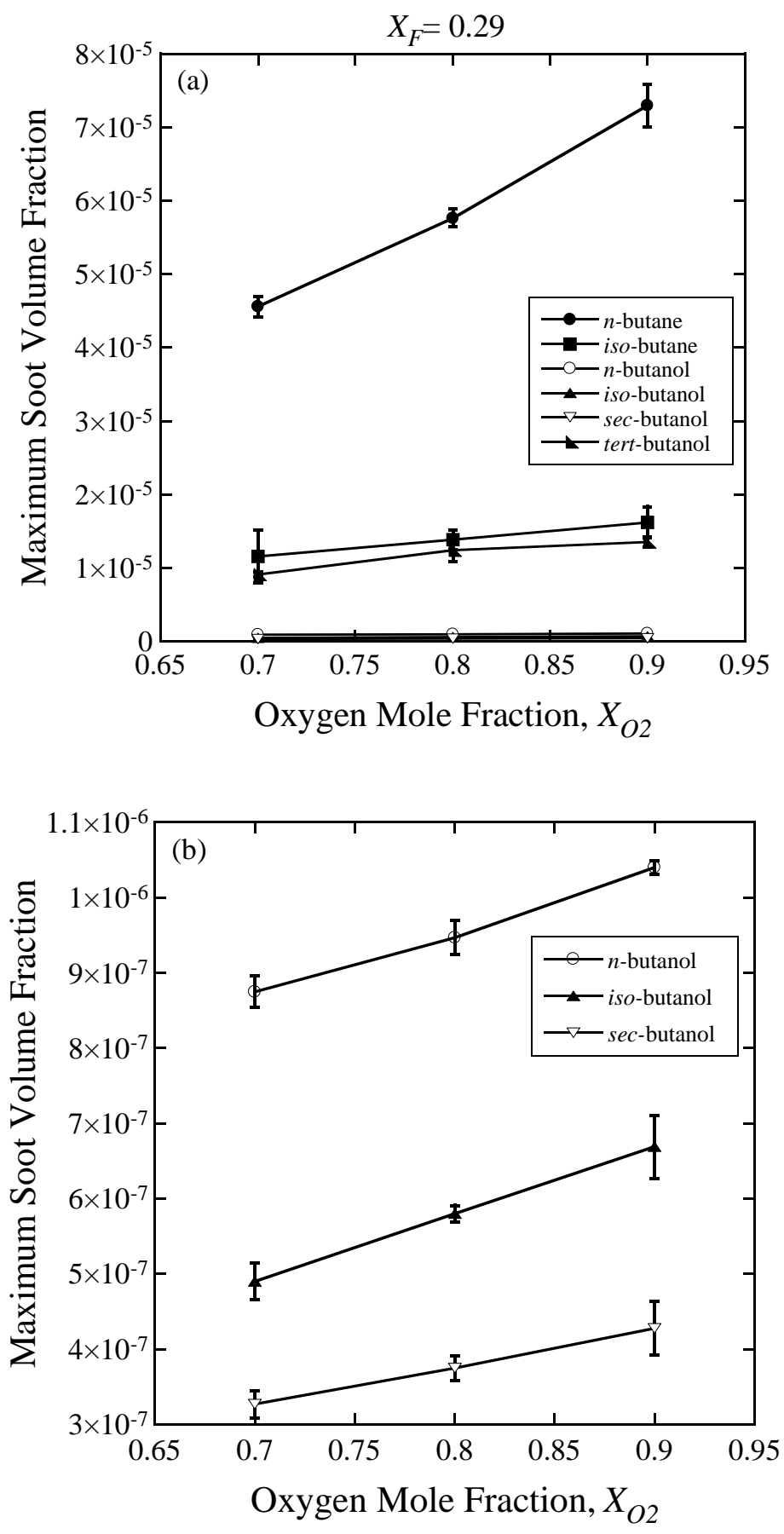

Figure 10 

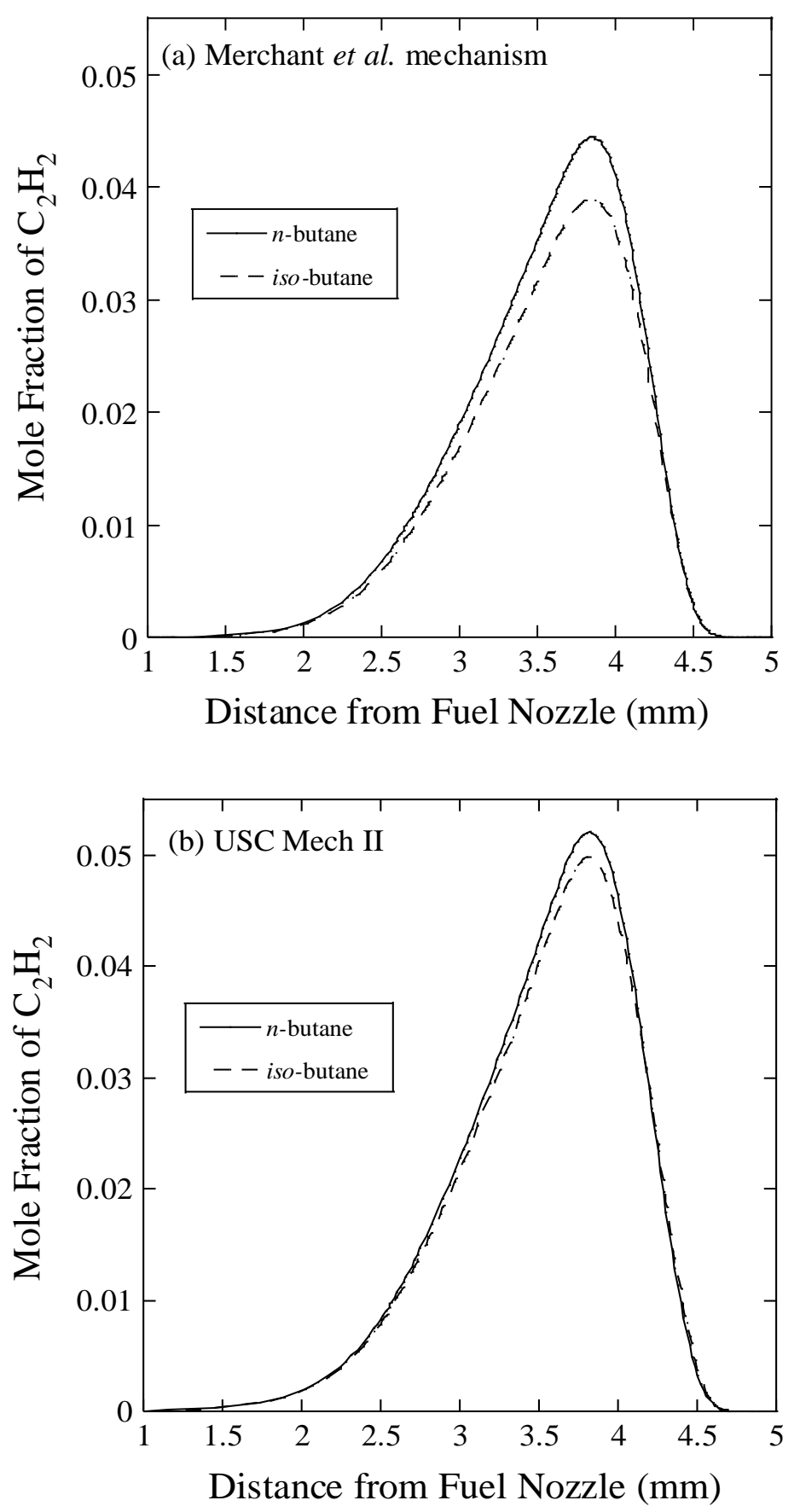

Figure 11 

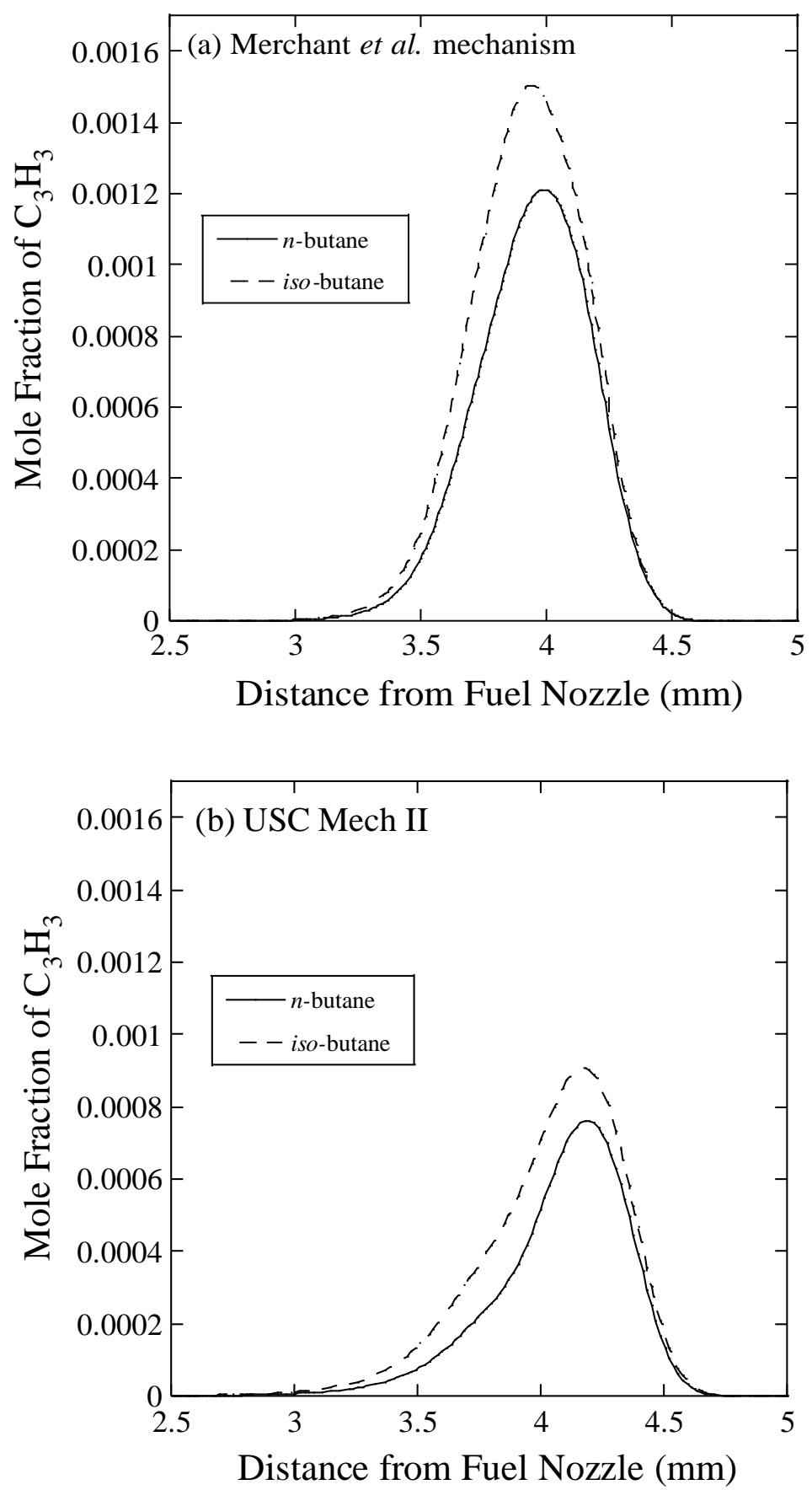

Figure 12 


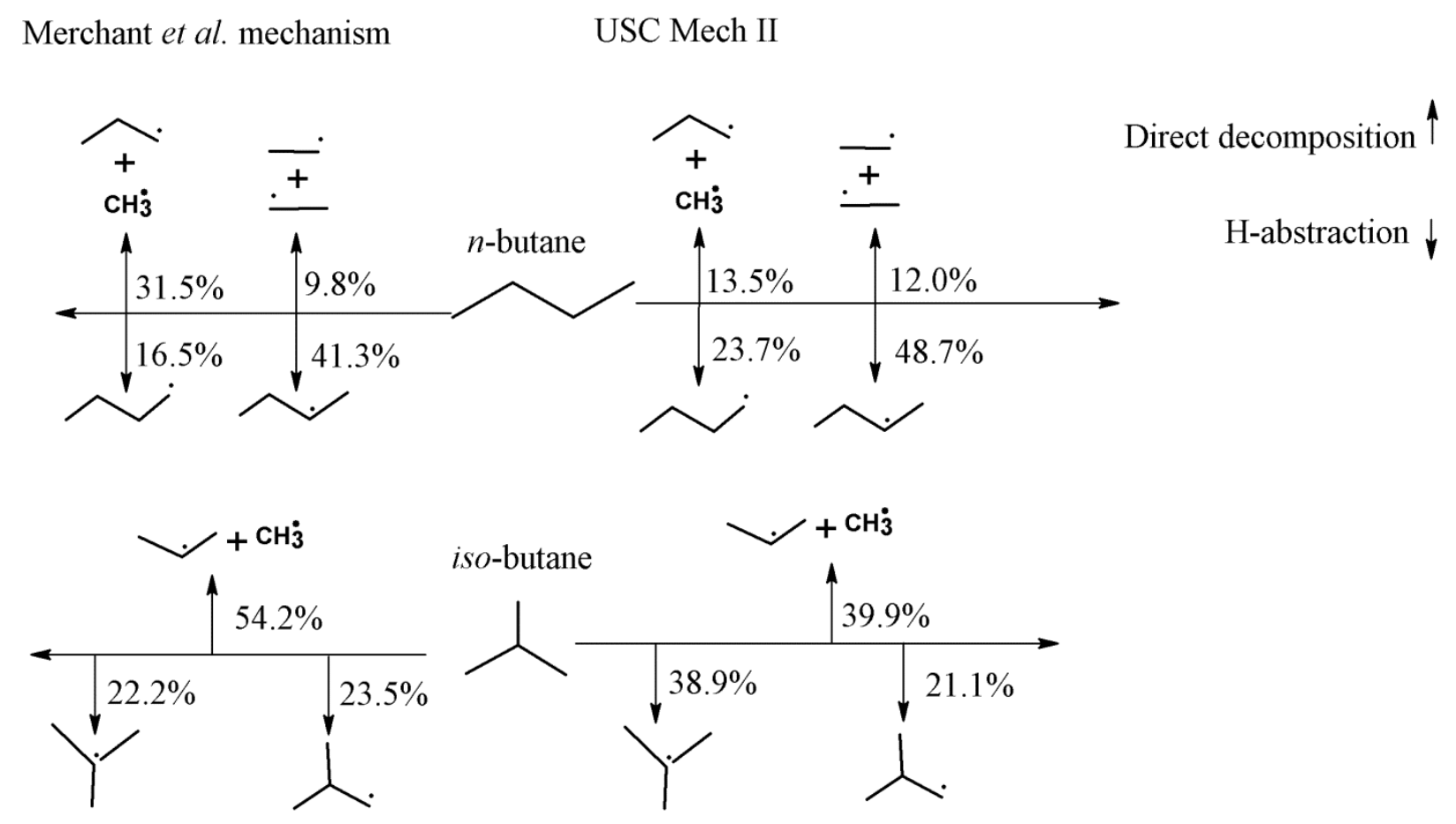

Figure 13 

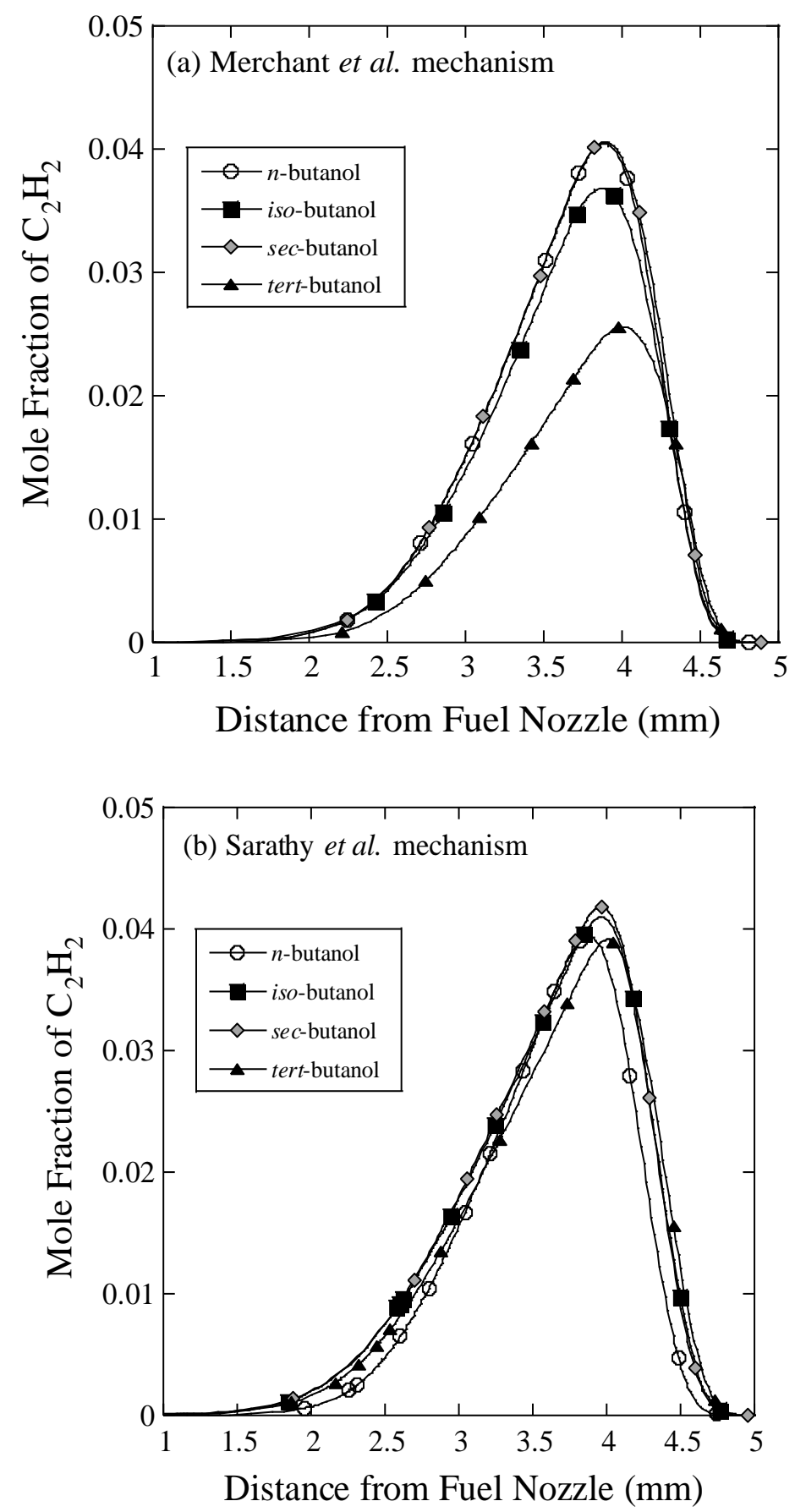

Figure 14 


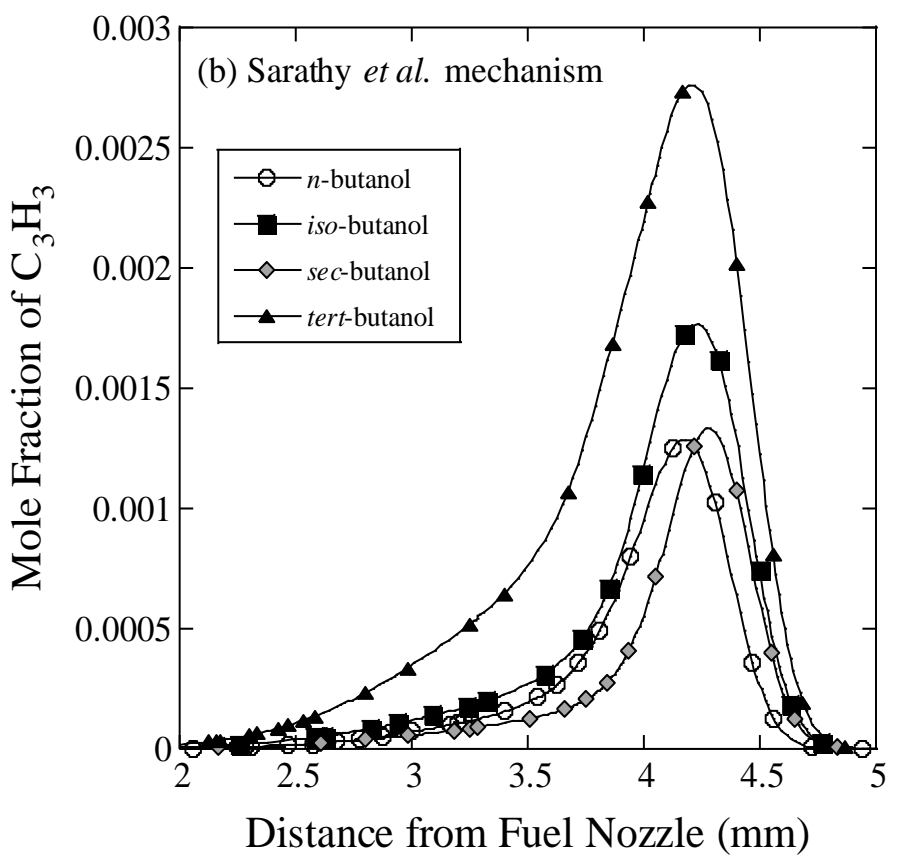

Figure 15 
Figure 16

Sarathy et al. mechanism
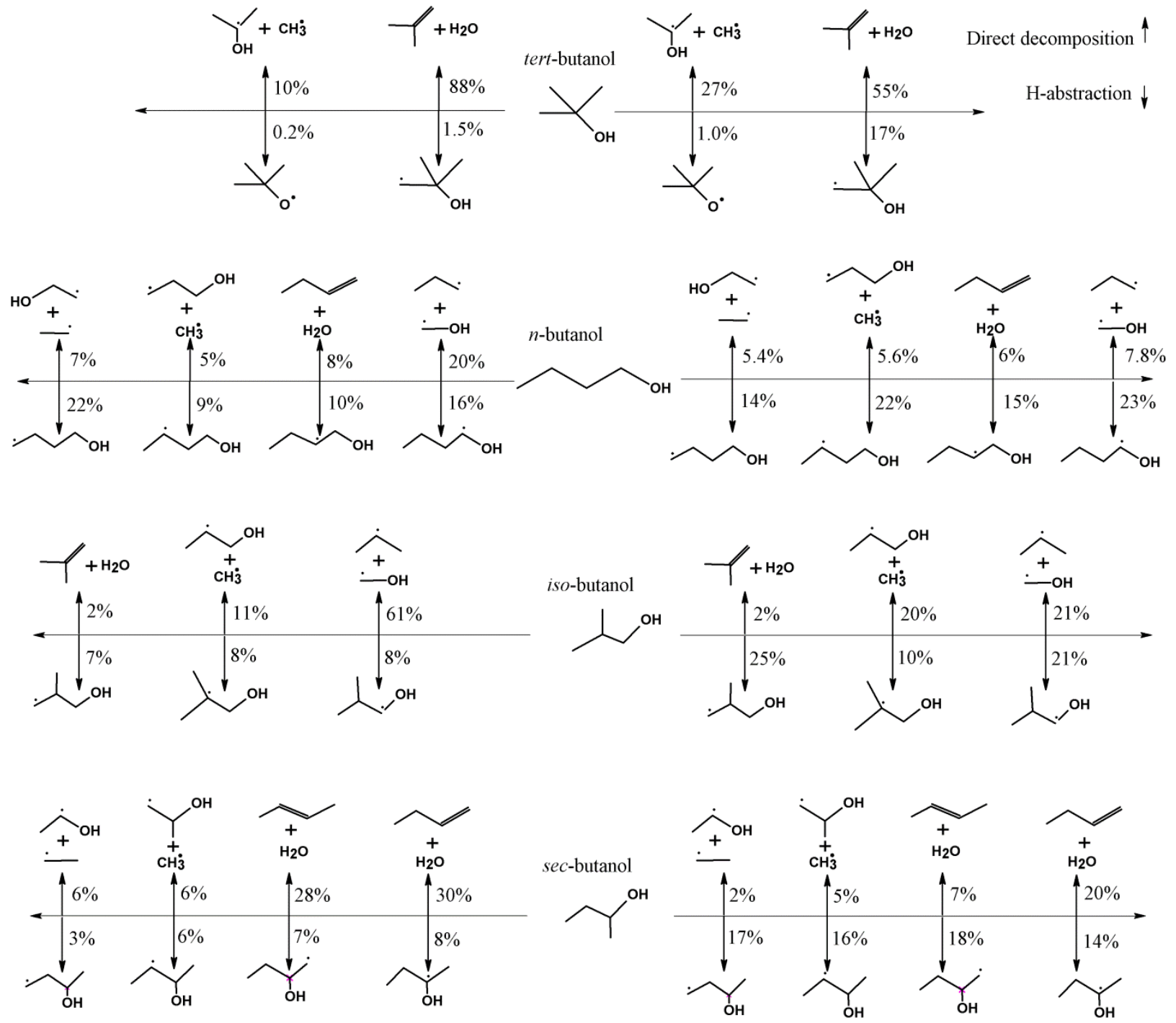
Table 1

\begin{tabular}{|c|c|c|c|c|c|}
\hline$n$-butane & iso-butane & $n$-butanol & iso-butanol & sec-butanol & tert-butanol \\
\hline & & & & $\mathrm{OH}$ & $\mathrm{OH}$ \\
\hline
\end{tabular}

Table 2

\begin{tabular}{|c|c|c|c|c|c|c|c|c|c|c|c|}
\hline \multicolumn{2}{|c|}{$\begin{array}{c}\text { Fuel } \\
\text { Stream }\end{array}$} & \multicolumn{2}{c|}{ Oxidizer } & \multicolumn{6}{|c|}{ Adiabatic Flame Temperature } & \multicolumn{2}{c|}{ Stoich. Mixture Fraction } \\
\hline$X_{F}$ & $X_{N_{2}}$ & $X_{O_{2}}$ & $X_{N_{2}}$ & $\begin{array}{c}n- \\
\text { butane }\end{array}$ & $\begin{array}{c}\text { iso- } \\
\text { butane }\end{array}$ & $\begin{array}{c}n- \\
\text { butanol }\end{array}$ & $\begin{array}{c}\text { iso- } \\
\text { butanol }\end{array}$ & $\begin{array}{c}\text { sec- } \\
\text { butanol }\end{array}$ & $\begin{array}{c}\text { tert- } \\
\text { butanol }\end{array}$ & $\begin{array}{c}\text { butane } \\
\text { isomers }\end{array}$ & $\begin{array}{c}\text { butanol } \\
\text { isomers }\end{array}$ \\
\hline 0.21 & 0.79 & 0.90 & 0.10 & 2944 & 2941 & 2898 & 2895 & 2892 & 2885 & 0.417 & 0.460 \\
\hline 0.22 & 0.78 & 0.90 & 0.10 & 2949 & 2947 & 2904 & 2901 & 2898 & 2890 & 0.408 & 0.451 \\
\hline 0.23 & 0.77 & 0.90 & 0.10 & 2955 & 2952 & 2910 & 2907 & 2904 & 2896 & 0.399 & 0.443 \\
\hline 0.24 & 0.76 & 0.90 & 0.10 & 2961 & 2958 & 2915 & 2912 & 2910 & 2902 & 0.391 & 0.436 \\
\hline 0.25 & 0.75 & 0.90 & 0.10 & 2966 & 2964 & 2921 & 2918 & 2915 & 2908 & 0.384 & 0.429 \\
\hline 0.26 & 0.74 & 0.90 & 0.10 & 2972 & 2969 & 2927 & 2924 & 2921 & 2914 & 0.376 & 0.422 \\
\hline 0.27 & 0.73 & 0.90 & 0.10 & 2978 & 2975 & 2933 & 2930 & 2927 & 2920 & 0.369 & 0.415 \\
\hline 0.28 & 0.72 & 0.90 & 0.10 & 2984 & 2981 & 2939 & 2936 & 2933 & 2926 & 0.363 & 0.409 \\
\hline 0.29 & 0.71 & 0.90 & 0.10 & 2989 & 2987 & 2945 & 2942 & 2939 & 2932 & 0.357 & 0.404 \\
\hline 0.29 & 0.71 & 0.80 & 0.20 & 2958 & 2955 & 2915 & 2912 & 2909 & 2902 & 0.333 & 0.379 \\
\hline 0.29 & 0.71 & 0.70 & 0.30 & 2919 & 2916 & 2877 & 2874 & 2872 & 2864 & 0.307 & 0.351 \\
\hline
\end{tabular}


Table 3

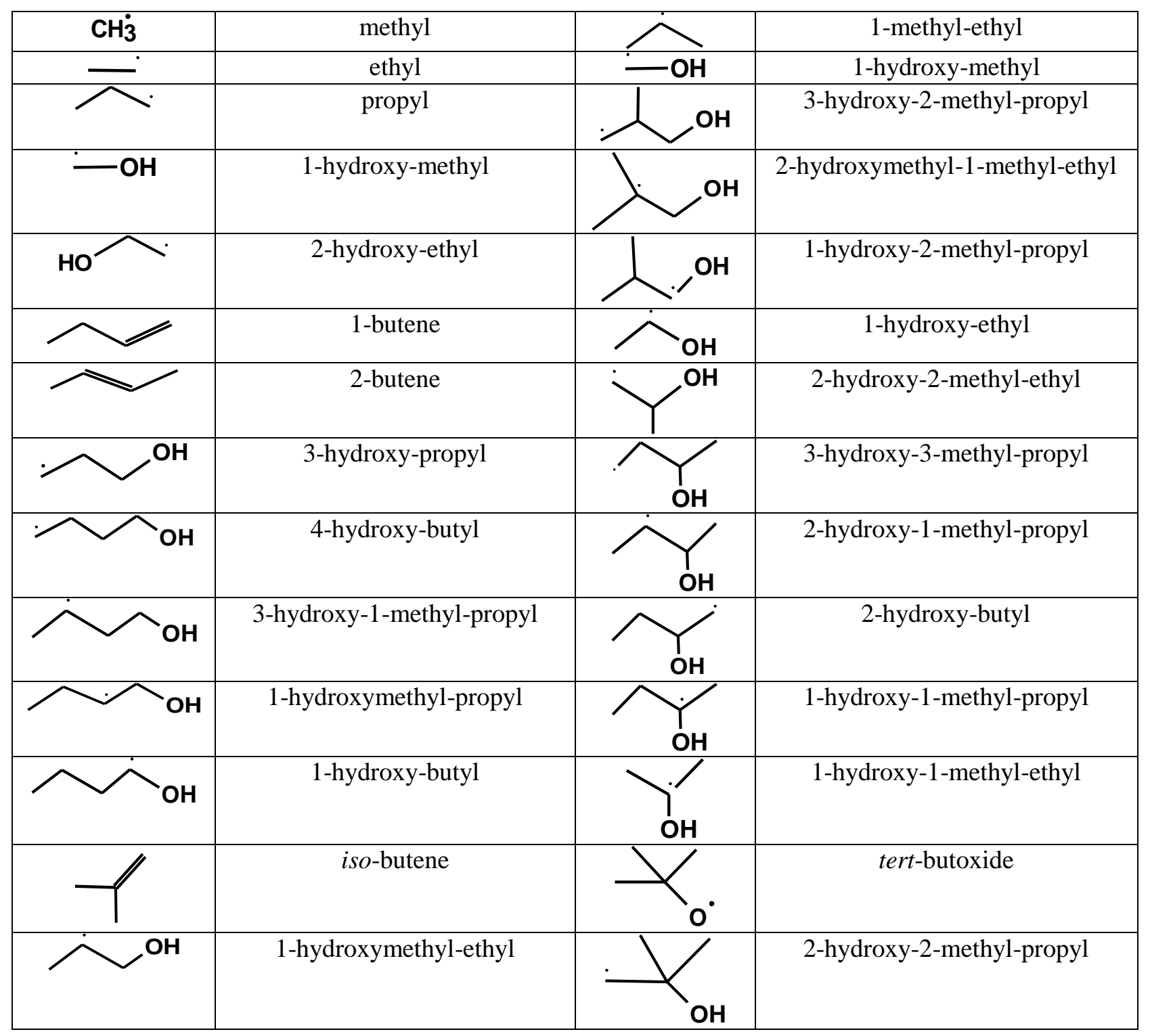

